\title{
Organization of Cerebral Projections to Identified Cerebellar Zones in the Posterior Cerebellum of the Rat
}

\author{
Lucia Suzuki, ${ }^{1}$ Patrice Coulon, ${ }^{2}$ Erika H. Sabel-Goedknegt, ${ }^{1}$ and Tom J. H. Ruigrok ${ }^{1}$ \\ ${ }^{1}$ Department of Neuroscience, Erasmus University Medical Center Rotterdam, 3000CA Rotterdam, The Netherlands, and ${ }^{2}$ Institut des Neurosciences de la \\ Timone, CNRS and Aix-Marseille Université, 13385 Marseille Cedex 05, France
}

The cerebrocerebellar connection makes use of two of the largest fiber tracts in the mammalian brain, i.e., the cerebral and medial cerebellar peduncles. Neuroanatomical approaches aimed to elucidate the organization of this important connection have been hindered by its multisynaptic nature, the complex organization of its components, and the dependency of conventional tracers on precisely placed injections. To overcome these problems, we used rabies virus (RV) as a retrograde transneuronal tracer. RV was injected simultaneously with cholera toxin $\beta$ subunit ( $\mathrm{CTb}$ ) into selected areas of the cerebellar cortex of 18 male Wistar rats. A survival time of $48-50 \mathrm{~h}$ resulted in first- and second-order labeling of RV in combination with first-order labeling of CTb. The distribution of CTb-labeled neurons in the inferior olive established the zonal identity of the injection site. In this way, it was possible to examine the cortical distribution of neurons from which disynaptic cerebrocerebellar projections to specific cerebellar loci originate.

The results show that this distribution covaries with the identity of the injected cerebellar lobule. More subtle changes were present when different zones of the same lobule were injected. The $\mathrm{C} 1$ zone of lobule VIII receives a more prominent projection from the somatosensory cortex compared with the C2/D zones. The laterally positioned $\mathrm{D}$ zones receive information from more rostral regions of the cerebral cortex. The vermis of lobule VII receives a prominent input from the retrosplenial and orbitofrontal cortices. Different injection sites also result in differences in laterality of the connections.

\section{Introduction}

The classic view that cerebellar functioning is confined to the coordination of motor activity has changed in recent years as it may also involve cognitive and affective functioning (Schmahmann and Sherman, 1998; Schmahmann and Caplan, 2006; Strick et al., 2009). Cerebellar influence on these cerebral functions not only requires a cerebellar impact on cerebral functioning but also entails the necessary communication between cerebrum and cerebellum.

Of the many routes of cerebrocerebellar communication, the cerebro-ponto-cerebellar pathway forms the most impressive as it uses two of the most prominent fiber bundles in the mammalian brain: i.e., the cerebral and the medial cerebellar peduncles. Nevertheless, the cerebral involvement in cerebellar functioning has remained underexposed for many years. To some extent this is due to the complex transformations that take place in the cerebro-ponto-cerebellar pathway (Leergaard et al., 2006). Approaches to understand its functional organization are hampered by its multisynaptic nature and complex organization (Leergaard et al., 2000b, 2006; Pijpers and Ruigrok, 2006); e.g., only scant

Received Feb. 22, 2012; revised June 18, 2012; accepted June 19, 2012.

Author contributions: P.C. and T.J.H.R. designed research; L.S., P.C., E.H.S.-G., and T.J.H.R. performed research; L.S. and T.J.H.R. analyzed data; L.S., P.C., and T.J.H.R. wrote the paper.

This study was supported by the Dutch Ministry of Health, Welfare and Sports (L.S., E.H.S.-G., T.J.H.R.) and the CNRS and Aix-Marseille Université through UMR 7289 (P.C.).

Correspondence should be addressed to Tom J. H. Ruigrok, Department of Neuroscience, Erasmus MC Rotterdam, P0 Box 2040, 3000CA Rotterdam, The Netherlands. E-mail: t.ruigrok@erasmusmc.nl.

DOI:10.1523/JNEUROSCI.0857-12.2012

Copyright $\odot 2012$ the authors $\quad 0270-6474 / 12 / 3210854-16 \$ 15.00 / 0$ information is available on the relation between the functional cerebral regions and the so-called fractured cerebellar maps (Welker, 1987; Bower, 2011) or with the olivocerebellar modules. These modules are based on the matching organizations of projections from the olivocerebellar climbing fibers to longitudinal strips or zones of the Purkinje cells, the projections from these Purkinje cells to the cerebellar nuclei and their subsequent and selective projection patterns (Ruigrok and Voogd, 2000; Teune et al., 2000; Sugihara and Shinoda, 2004; Voogd and Ruigrok, 2004; Pijpers et al., 2005; Apps and Hawkes, 2009; Ruigrok, 2011). The resulting parasagittally organized circuits are referred to as modules, some of which have been subdivided into micromodules, and are seen as the functional units of the cerebellum (Apps and Garwicz, 2005; Ruigrok et al., 2008; Ruigrok, 2011). Recent studies show that the distribution of pontocerebellar connections, at least partly, may be closely related to that of climbing fibers (Odeh et al., 2005; Pijpers et al., 2006). The present study aims to describe and understand the cerebrocerebellar pathway in both a comprehensive and functional way by attempting to relate the cerebrocerebellar organization to that of the cerebellar modular organization in the rat.

Cerebrocerebellar projections to the posterior cerebellum (Pijpers and Ruigrok, 2006) were charted using the retrograde transneuronal transport characteristics of rabies virus (RV) (Ugolini, 2010). A mixture of RV and a classic tracer (cholera toxin $\beta$-subunit; $\mathrm{CTb}$ ) was injected at various locations of the posterior lobe of the cerebellar cortex of the rat. Survival time was set to allow either first-order, second-order, or third-order transneuronal RV infection to occur. CTb only labels first-order 
Table 1. Overview of experimental cases grouped by injection site and survival time

\begin{tabular}{|c|c|c|c|c|c|c|c|c|c|c|c|c|c|c|c|c|}
\hline \multirow{2}{*}{$\begin{array}{l}\text { Experiment } \\
\text { no. }\end{array}$} & & & \multirow{2}{*}{$\begin{array}{l}\text { Volume } \\
\text { (nl) }\end{array}$} & \multirow{2}{*}{$\begin{array}{l}\text { Survival } \\
\text { (h) }\end{array}$} & \multicolumn{3}{|c|}{$\begin{array}{l}\text { No. of CTb } \\
\text { neurons I0 }\end{array}$} & \multirow[b]{2}{*}{ Zone } & \multicolumn{4}{|c|}{ No. of CTb neurons } & \multirow[b]{2}{*}{ RV cortex } & \multicolumn{2}{|c|}{$\begin{array}{l}\text { No. of plotted RV } \\
\text { neurons }\end{array}$} & \multirow{2}{*}{$\begin{array}{l}\text { Lat. index } \\
\text { no. cx (R)/ } \\
\text { no. cx (L) }\end{array}$} \\
\hline & \multicolumn{2}{|c|}{ Injection right Cbl } & & & DAO & $\mathrm{PO}$ & MAO & & $\operatorname{NRTP}(\mathrm{L})$ & $\operatorname{NRTP}(R)$ & $\mathrm{BPN}(\mathrm{L})$ & $\mathrm{BPN}(\mathrm{R})$ & & Cortex (L) & Cortex (R) & \\
\hline 1076 & VIII & paravermis & 200 & 30 & 321 & 0 & 70 & C1 & 185 & 28 & 1253 & 21 & no labeling & - & - & - \\
\hline 1079 & VIII & paravermis & 200 & 50 & 596 & 10 & 120 & $\mathrm{C} 1$ & 227 & 34 & 2099 & 90 & layer V & 1787 & 115 & 0.06 \\
\hline 1078 & VIII & paravermis & 200 & 50 & 384 & 0 & 176 & $C 1-C X$ & 331 & 42 & 2273 & 128 & layer V & 1743 & 207 & 0.12 \\
\hline 1101 & VIII & paravermis & 150 & 48 & 483 & 1 & 208 & $C 1-C X$ & 316 & 45 & 2270 & 86 & layer V & 2704 & 155 & 0.06 \\
\hline 1093 & VIII & hemisphere & 200 & 48 & 3 & 80 & 214 & $\mathrm{C} 2$ & 418 & 116 & 1431 & 167 & layer V & 3443 & 1067 & 0.31 \\
\hline 1075 & VIII & hemisphere & 200 & 50 & 0 & 175 & 239 & $C 2-D$ & 605 & 162 & 2369 & 267 & layer V & 644 & 170 & 0.26 \\
\hline 1073 & VIII & paravermis & 200 & 70 & 496 & 7 & 75 & C1 & 282 & 29 & 2088 & 171 & layer II-VI & n.d. & n.d. & - \\
\hline 1123 & VII & vermis & 200 & 48 & 0 & 42 & 341 & $\mathrm{~A} 1$ & 1053 & 1105 & 3127 & 3614 & layer V & 4519 & 3749 & 0.83 \\
\hline 1124 & VII & vermis & 200 & 48 & 0 & 40 & 278 & $\mathrm{~A} 1$ & 1059 & 1158 & 3703 & 3471 & layer V & 3117 & 3286 & 1.05 \\
\hline 1095 & VII & vermis & 150 & 48 & 0 & 52 & 183 & $\mathrm{~A} 1$ & 501 & 424 & 2206 & 1643 & layer V & 692 & 602 & 0.87 \\
\hline 1126 & VII-PM & paravermis & 200 & 48 & 189 & 8 & 325 & $A 2-C$ & 229 & 182 & 1222 & 503 & layer V & 2965 & 1023 & 0.35 \\
\hline 1080 & VII-PM & paravermis & 200 & 50 & 98 & 0 & 280 & $C 2$ & 194 & 161 & 1748 & 273 & layer V & 549 & 57 & 0.10 \\
\hline 1125 & VII-PM & paravermis & 200 & 48 & 214 & 74 & 325 & $\mathrm{C} 2-\mathrm{C} 3$ & 272 & 214 & 1902 & 351 & layer V & 3873 & 1170 & 0.30 \\
\hline 1127 & VII-PM & hemisphere & 200 & 48 & 0 & 224 & 0 & $\mathrm{D} 2$ & 268 & 183 & 2199 & 243 & layer V & 3381 & 763 & 0.23 \\
\hline 1074 & VII-PM & paravermis & 200 & 70 & n.d. & n.d. & n.d. & n.d. & n.d. & n.d. & n.d. & n.d. & layer II-VI & n.d. & n.d. & - \\
\hline 1098 & VII-crus II & paravermis & 150 & 48 & 537 & 490 & 360 & $C-D$ & 308 & 303 & 2117 & 449 & layer V & 2306 & 505 & 0.22 \\
\hline 1099 & VII-crus II & hemisphere & 150 & 48 & 16 & 1027 & 0 & $D$ & 402 & 360 & 3126 & 620 & layer V & 3025 & 1050 & 0.35 \\
\hline 1077 & VII-crus II & hemisphere & 150 & 70 & 1 & 792 & 2 & D2 & 557 & 454 & 4853 & 832 & layer II-VI & n.d. & n.d. & - \\
\hline
\end{tabular}

Counts of the number of plotted (Tb cells in the contralateral inferior olive and contralateral (L) and ipsilateral (R) pontine nuclei (based on a complete series of one of four sections) are provided for most cases; as well, the number of RV-labeled cortical cells (based on a one of eight series of sections) are provided. Zonal identification based on Voogd and Ruigrok (2004). See also Apps and Hawkes (2009). Cx, Cortex; L, left side (contralateral); Lat. Index, laterality index; n.d., not determined; $R$, right side (ipsilateral); PM, paramedian lobule. For other abbreviations see Fig. 1.

neurons and allows a correlation of the modular identity of the injection site with the cerebral cortical labeling. We show that the cerebrocerebellar organization relates to both the lobular as well as to the modular organization of the cerebellum but also provide evidence that cerebellar regions receive disynaptic input from cerebral regions that are involved in nonmotor functions. A preliminary report has been presented in abstract form (Suzuki et al., 2010).

\section{Materials and Methods}

This study is based on results obtained in 18 adult, male Wistar rats (weight 200-300 g). All procedures adhered to the European guidelines for the care and use of laboratory animals. Vaccinated personnel conducted all RV experiments at the appropriate biosafety containment level (level 2).

Surgical procedure. Before surgery, animals were anesthetized intraperitoneally with a mixture of ketamine $(60 \mathrm{mg} / \mathrm{kg}$; Imalgene, Merial) and xylazine $(10 \mathrm{mg} / \mathrm{kg}$; Rompun, Bayer). Surgical levels of anesthesia were monitored by the absence of rhythmic whisker movements and pinch withdrawal reflex. When necessary, supplementary doses were administered to maintain surgical levels of anesthesia. During surgery, body temperature was monitored and kept within physiological limits ( $37 \pm$ $1^{\circ} \mathrm{C}$ ). After inducing anesthesia, the animals were placed in a stereotactic head holder (David Kopf Instruments), the skin overlying the occipital bone and neck was cut, the neck muscles were separated in the midline and the foramen magnum was enlarged in dorsal direction using a rongeur. In this way, the vermis and right side of the posterior cerebellum were exposed after which the dura overlying the cerebellum was carefully cut and reflected.

Injections were placed under visual guidance into selected parts of either lobule VIII (copula pyramidis, $n=6$ ), vermis of lobule VII and paramedian lobule $(n=10)$, or crus IIb $(n=2)$ of the cerebellar cortex (Table 1). Injections were made with an adapted Hamilton syringe of 10 $\mu \mathrm{l}$, the plunger of which was moved by a programmable microsyringe pump (flow $200 \mathrm{nl} / \mathrm{min}$ ), connected by way of thin tubing (inner diameter, $0.1 \mathrm{~mm}$ ) in which the movement of an air bubble was monitored to enable control of the injected volume. The injectate contained a mixture of 1 part 1\% CTb (low salt; List Biological Laboratories, $1 \% \mathrm{w} / \mathrm{v}$ in $0.2 \mathrm{M}$ phosphate buffer, $\mathrm{pH}$ 7.4) and 4 parts RV (Ruigrok et al., 2008; Prevosto et al., 2009). For these experiments the "French" subtype of Challenge Virus Standard (CVS) strain was used (for a clarification on the different CVS strains, see Ugolini, 2010), which has been used in previous RV tracing experiments (Ugolini, 1995; Ugolini et al., 2006; Ruigrok et al., 2008; Salin et al., 2008, 2009; Coulon et al., 2011). RV consisted of a cell culture supernatant in minimal essential medium titrating $4 \times 10^{7}$ plaque-forming units/ml. Either 150 or $200 \mathrm{nl}$ was injected at a depth of $300-600 \mu \mathrm{m}$ below the surface. In all cases the needle was kept 3-5 min in place. The actual location and spread of the injectate was determined afterward by evaluation of the CTb staining as well as by mapping the distribution of CTb-labeled neurons in the inferior olive (IO) (Voogd et al., 2003; Pijpers and Ruigrok, 2006). Following each injection, the wound was sutured and the animals were allowed to recover. All animals were monitored carefully for behavioral changes, at which point the experiment would be terminated. However, as expected, the survival times used (30-70 h) were asymptomatic (Ugolini, 2010).

Initially, eight animals were injected with the RV/CTb mixture into selected regions of the cerebellar cortex (cases 1073-1080; Table 1). They were allowed to survive $30(n=1), 50(n=4)$, or $70(n=3) \mathrm{h}$. Analysis of these cases indicated that a $50 \mathrm{~h}$ survival period was sufficient to allow for retrograde transneuronal transport from the cerebellar injection site to the cerebral cortex (i.e., second-order connections). At this time no labeling of neurons outside layer $\mathrm{V}$ was noted. Moreover, no thalamic labeling was noted anywhere. Therefore, in another 10 animals, RV/CTb injections were made into the cerebellar cortex and these animals were allowed to survive $48 \mathrm{~h}$.

At the end of the survival time, rats were given a lethal dose of sodium pentobarbitone (100 mg/kg, i.p.; Nembutal, CEVA Santé Animale). Following an initial transcardial flush of $0.9 \%$ saline, they were perfusionfixed by cannulation of the ascending aorta and subsequent infusion of $4 \%$ paraformaldehyde (PFA) in PBS, pH 7.4. Afterward, brain and spinal cord were removed and postfixed for several days to kill the virus (Kelly and Strick, 2000).

Histology. Before further processing, the tissue was stored overnight in $0.05 \mathrm{M}$ phosphate buffer (PB) containing $10 \%$ sucrose at $4^{\circ} \mathrm{C}$. Subsequently, the brain together with the spinal cord, which was cut in three or four parts, were embedded in gelatin. The gelatin block was hardened for $3 \mathrm{~h}$ in a $10 \%$ formaldehyde solution containing 30\% sucrose at room temperature (RT) and stored overnight in $0.05 \mathrm{M}$ PB containing $30 \%$ sucrose at $4^{\circ} \mathrm{C}$. Sections were cut transversally on a freezing microtome (Leica SM 2000R) at $40 \mu \mathrm{m}$ and serially collected in eight numbered glass vials containing $0.05 \mathrm{M}$ PB such that every vial contained a complete one of eight series of sections.

The free-floating sections of two vials (number 1 and number 5) were incubated $48-72 \mathrm{~h}$ at $4^{\circ} \mathrm{C}$ in an anti-rabies phosphoprotein mouse 
monoclonal antibody diluted 1:5000 in PBS that contained 2\% normal horse serum and $0.5 \%$ Triton X-100 (PBS+). This antibody (31G10) was isolated in the laboratory Virologie Moléculaire et Structurale (formerly Génétique des Virus), Gif-sur-Yvette, France, during the fusion experiment described by Raux et al. (1997) and has been used in many tracing studies using rabies virus (Viemari et al., 2004; Ruigrok et al., 2008; Coulon et al., 2011). Subsequently, sections were rinsed before they were incubated in a rabbit anti-mouse horseradish peroxidase (P260 Dako, 1:200 in PBS +, 90 min at RT) After rinsing, the vials were incubated for 20-25 $\mathrm{min}$ in a 3,3'-diaminobenzidine-tetrahydrochloride solution (DAB+: $0.025 \% \mathrm{DAB}$ and $0.005 \% \mathrm{H}_{2} \mathrm{O}_{2}$ in $0.05 \mathrm{M} \mathrm{PB}$, at $\mathrm{RT}$ ) for visualization.

Two other vials (number 2 and number 6) were incubated $48-72 \mathrm{~h}$ at $4^{\circ} \mathrm{C}$ in a goat anti-CTb antibody (List Biological Laboratories, diluted 1:15,000 in PBS+). Subsequently, sections were incubated in biotinylated rabbit anti-goat (Vector Laboratories; 1:200 in PBS+, $90 \mathrm{~min}$ ), rinsed in $0.05 \mathrm{M} \mathrm{PB}$, and reacted with avidin-biotin complex (Vector Laboratories, $\mathrm{ABC}$ Elite kit) at half the recommended concentration in $\mathrm{PBS}+$ for $90 \mathrm{~min}$ at $\mathrm{RT}$, rinsed, and reacted with $\mathrm{DAB}+$. Finally, all sections were mounted serially from chromic alum, counterstained with thionin, dehydrated in a graded ethanol series, cleared in xylene, and then coverslipped with Permount.

In some animals, two of the remaining vials were selected to label RV and $\mathrm{CTb}$ in the same sections using combined fluorescent immunolabeling. The sections in these vials were incubated in a mixture of mouse anti-rabies (1:5000) and goat anti-CTb $(1: 15,000)$ in PBS + for $48-72 \mathrm{~h}$ at $4^{\circ} \mathrm{C}$. After rinsing in PBS, the sections were incubated for $2 \mathrm{~h}$ with the secondary antibodies (donkey anti-goat-Cy3, 1:200; and donkey antimouse-FITC, 1:200 in PBS+; Jackson ImmunoResearch Europe Inc). Finally, sections were mounted sequentially from chromic alum and coverslipped with Vectashield HardSet Mounting Medium (H-1400, Vector Laboratories).

Sections with fluorescent label were examined with a Leica DMRBE microscope using the appropriate filters and photographed with a Hamamatsu camera (C4880). Photo panels of Figure 3 (see below) were constructed in Adobe Photoshop CS3.

Analysis. Assessment of the progress of viral infection was done by careful analysis of labeled structures in thionin-counterstained sections. Photomicrographs were made with a Leica DMR microscope equipped with a digital camera (Leica DC-300). The photo panel of Figure 2 (see below) was constructed in CorelDraw 11.0, after some correction for brightness and contrast in Corel Photopaint 11.0.

As the cerebellum consists of parasagittal zones that define fundamental modules of neural processing and each zone receives input from a distinct subdivision of the $\mathrm{IO}$, neuronal labeling with $\mathrm{RV} / \mathrm{CTb}$ within the IO was used to determine the actual place and spread of the injection in terms of zonal organization as reported by Voogd and collaborators (Voogd et al., 2003; Voogd and Ruigrok, 2004; Pijpers and Ruigrok, 2006; Pijpers et al., 2008). The relevant zones in the posterior cerebellum and the olivary areas that form the origin of the climbing fibers to these zones are shown in Figure 1E. In addition to the IO, both RV and CTb labeling was systematically analyzed in the basal pontine nuclei (BPNs) and the nucleus reticularis tegmenti pontis (NRTP) as was RV labeling within the cerebral cortex. In some animals labeling was analyzed in several other precerebellar nuclei such as the lateral reticular nucleus and the dorsal column nuclei, but we will not report on these data here.

Sections were plotted using a motorized Olympus BH microscope equipped with a Lucivid miniature monitor (MicroBrightField). The location of labeled neurons was indicated together with the contours of the section and relevant nuclei using Neurolucida software (MicroBrightField). Maps of either CTb or RV labeling in the precerebellar nuclei (IO, BPNs, NRTP) were based on sequential series of one of four sections (i.e., every $160 \mu \mathrm{m}$ ). Maps of the RV labeling in the cerebral cortex were based on sequential series of one of eight sections (i.e., every $320 \mu \mathrm{m}$ ), resulting in series of coronal plots throughout these structures. Subsequently, either an $80-\mu \mathrm{m}$-wide rectangle overlay for plots of the inferior olive, a $160-\mu \mathrm{m}$-wide rectangle overlay for the pontine nuclei, or a $320-\mu \mathrm{m}$-wide binned line overlay centered over layer $\mathrm{V}$ of the cerebral cortex was used to count the number of labeled neurons within every grid bin (Fig. 1). Note that the position of the inferior olive was rotated $20^{\circ}$ clockwise to obtain maximal correspondence of the position of the olivary sheets and the rectangular grid (Fig. $1 \mathrm{~A}$ ). The obtained numbers served as a measure of the density of labeled neurons. Using standard Matlab (MathWorks) routines and interpolation (Ruigrok, 2003; Pijpers and Ruigrok, 2006), the data were visualized as color-coded density plots (Fig. 1). The 320- $\mu \mathrm{m}$-wide bins overlaying layer $\mathrm{V}$ of the cerebral cortex of sequential sections were aligned with respect to the most dorsomedial bin. In this way, a flattened representation of the entire cerebral cortex was made (Fig. 1C). An analogous transformation was carried out on the basis of the stereotactic atlas of Paxinos and Watson (2005) resulting in a similarly appearing representation of the flattened cerebral cortex on which the various functional areas are indicated (Fig. 1D). This map served as an overlay for the color-coded density maps of the cortical RV labeling thus enabling identification of areas with labeling and comparison between experimental cases. Because at survival time of $30 \mathrm{~h}$ no labeling was seen in the cerebral cortex, whereas at $70 \mathrm{~h}$ postinjection, multiple cortical layers became infected and thalamic labeling was evident, indicating that third-order infection has occurred, the cerebral cortex was plotted only for animals that survived $48-50 \mathrm{~h}$ postinjection.

\section{Results}

\section{Survival time and progression of RV and CTb labeling}

As an initial step, we have examined the effect of survival time on the rate of transneuronal RV transport. Previous reports have indicated that infection of first-order neurons requires more time than the sequentially occurring labeling of second- and thirdorder labeling (Ugolini, 2010). Moreover, species type, type and titer of the rabies virus used, and characteristics of the pathway investigated may all induce variations in the speed of uptake, transport, replication and transneuronal infection characteristics (Ugolini, 1995, 2010; Ruigrok et al., 2008; Coulon et al., 2011). In the present study, we want to describe the disynaptic cerebrocerebellar connection, dominated by the cerebro-ponto-cerebellar pathway, which required that the virus should not exceed secondorder infection stages. Based on earlier experience (Ruigrok et al., 2008; Salin et al., 2008; Coulon et al., 2011), three survival times, 30,50 , and $70 \mathrm{~h}$, were selected for initial examination. Figure 2 shows the labeling results of three cases (1076-30 h, Fig. 2A; 1079-50 h, Fig. $2 B$; 1073-70 h, Fig. 2C), which all received an injection into the paravermis of lobule VIII. The location and spread of injectate can be appreciated by the CTb labeling. Although the injectate usually also invaded the white matter to some extent and CTb has been reported to be taken up by passing fibers (Chen and Aston-Jones, 1995), this is not deemed to bias our results as the white matter compartments directly subjacent to the cortical zones contain both the efferents and the afferents of the cortical region covered by the injection (Voogd, 2004). RV injected into the CNS has not been reported to be taken up by passing fibers (Ugolini, 2010). Moreover, retrograde labeling patterns within the inferior olive (see below) matched the labeling observed using anterograde techniques (Sugihara and Shinoda, 2004; Voogd and Ruigrok, 2004). Finally, as explained below, there was a precise match between the CTb and RV labeling patterns in inferior olive and basal pontine nuclei.

The injection of all three cases was centered on the C1-zone as was established by the prominent retrograde CTb labeling of olivary neurons in the lateral halve of the dorsal accessory olive (DAO) of the contralateral side. Spread of the injectate to the adjacent CX zone (Atkins and Apps, 1997; Voogd et al., 2003; Voogd and Ruigrok, 2004) was evident by labeling of some cells in the intermediate part of the medial accessory olive (MAO; Fig. $2 A 2-C 2$; cf. Fig. $1 E$ ). Note that there is no obvious distinction in the distribution of the olivary labeling in these three cases with different survival times. In alternate sections incubated for RV, 
A

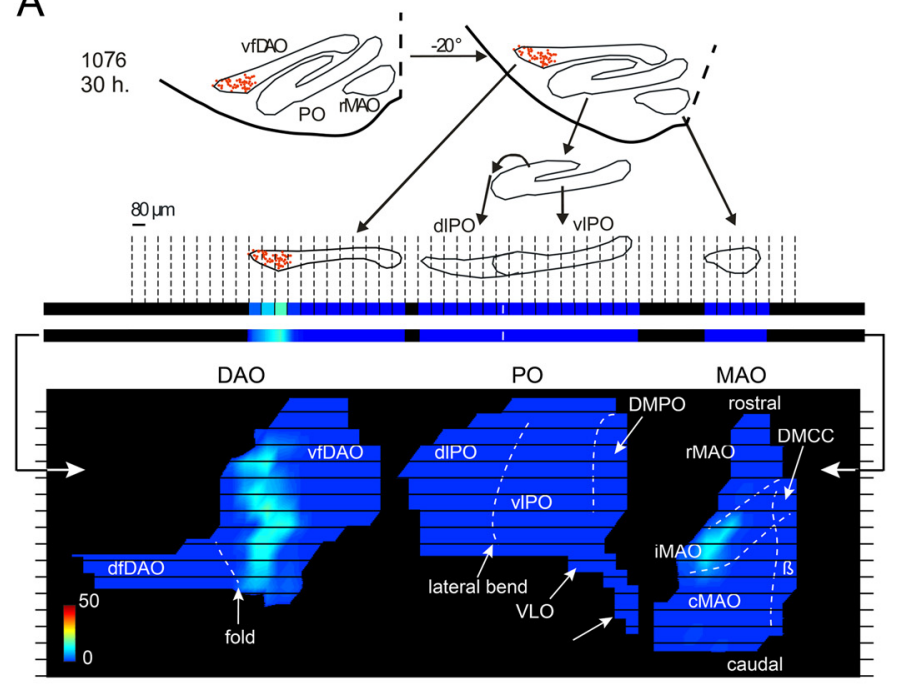

C

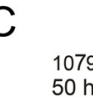

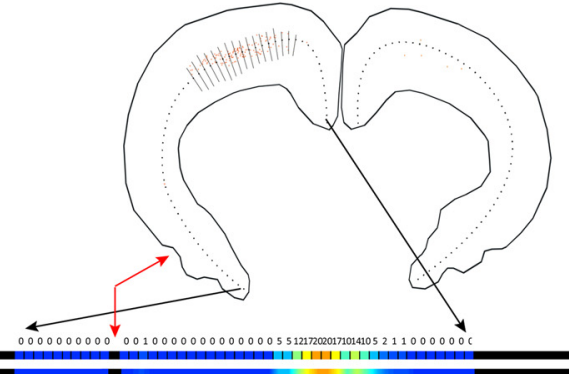
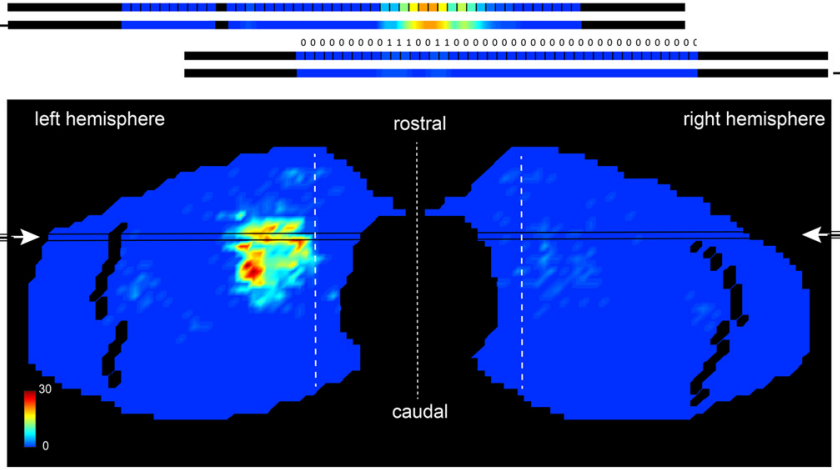

$\mathrm{E}$

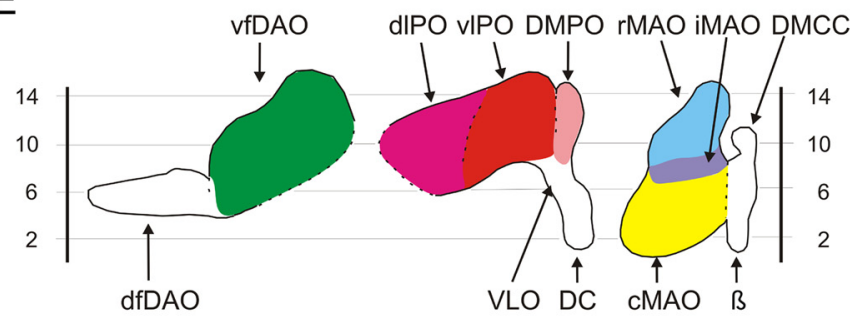

B
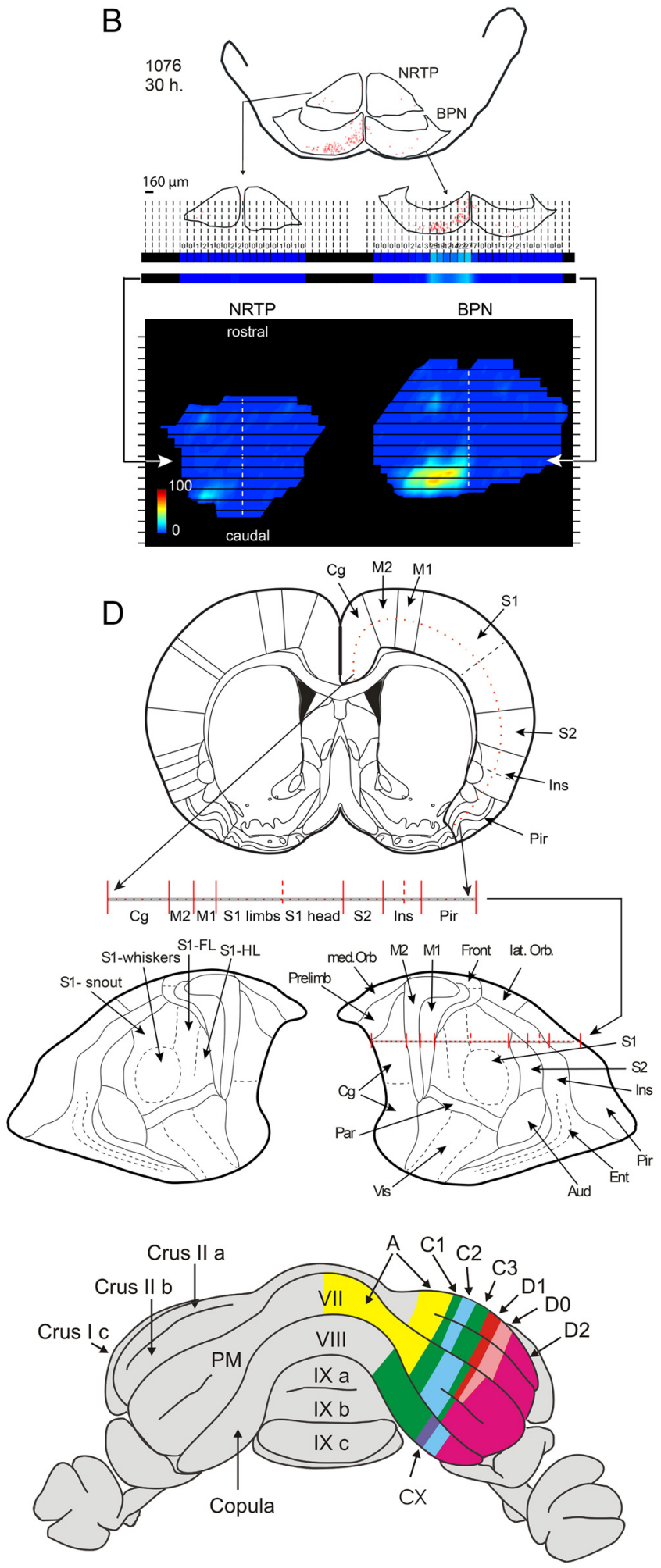

Figure 1. Construction of color-coded density maps of flattened surface representations. $A$, Example plot of a section of the inferior olive with CTb-labeled neurons in the lateral part of the DAO (case 1076). Each red dot represents a CTb-labeled neuron. After clockwise rotation $\left(20^{\circ}\right)$, the three main olivary subnuclei were unfolded (PO and DAO), separated, and superimposed with $80-\mu \mathrm{m}$-wide bins in which the number of labeled neurons was indicated. A similar conversion was made for all analyzed sections containing the inferior olive and incubated for $\mathrm{CTb}$ (based on a series of one of four sections). The resultant matrix was entered in Matlab in which a color-coded and interpolated density profile of a dorsal representation of the inferior olive was generated (bottom). $B$, An analogous conversion was also prepared for the pontine nuclei with separate representation of the NRTP and the BPN. Here, a bin width of $160 \mu \mathrm{m}$ was chosen and the color-coded density map was also based on a complete series of one of four sections. C, For the cerebral cortex, a binned line was morphed over layer V. Bin separation marks run perpendicular to this line and plotted cells were counted within bins. The bin line was straightened and numbers were entered in Matlab. Bins were $320 \mu \mathrm{m}$ wide and cortical representation is based on a one of eight series of analyzed sections. The bins overlying the rhinal fissure (red arrows) are shown as a thick black line. D, A similar transformation was carried out on the diagrams of the rat stereotactic atlas (Paxinos and Watson, 2005), resulting in a diagram of the flattened cortex on which the various cytoarchitectonic and functional areas are indicated and which was superimposed on the cortical color-coded density profiles. $\boldsymbol{E}$, Schematic representation of the olivocerebellar projection zones. The inferior olive (left) is depicted as explained in A. Color-coded areas contain olivary neurons that (Figure legend continues.) 
the same olivary areas also contained RV-infected cells. Here also, it was noted that increasing the survival time did not conspicuously influence the location of RV-labeled olivary neurons, although the number of RV-labeled olivary neurons in a complete series of one out four sections was clearly enhanced (from 55, in case 1076 , to 215 , in case 1079 , and 320 , in case 1073). This is in contrast with the number of CTb-labeled neurons in these cases which were all of the same magnitude (see Table 1). Because RV labeling in other areas indicated that with these increasing survival times the virus indeed did progress transneuronally, these data can be taken as evidence that connections within the cerebellum are predominantly based on modular (i.e., zonal) characteristics, as second- and even third-order labeling within the inferior olive did not expand beyond the boundaries of CTb labeling. Routes which may cause second- or third-order labeling in the inferior olive could involve recurrent axon collaterals of Purkinje cells, connections involving interneurons and nucleocortical connections followed by uptake by way of climbing fiber collaterals to the cerebellar nuclei (Ruigrok and Voogd, 2000), and, for third-order olivary labeling, routes involving precerebellar nuclei and nucleo-bulbar projections (Teune et al., 2000).

Observations similar to that in the inferior olive can also be made for the pontine nuclei. As reported earlier (Pijpers and Ruigrok, 2006), injection of the paravermal region of lobule VIII results in retrograde labeling that is mostly found in the ventromedial aspect of the caudal basal pontine nucleus (BPN) as well as ventromedially in the reticular NRTP (Fig. 2A4-C4). These same regions also contain RV-labeled neurons at all three survival times (Fig. 2A5-C5). The observations of the distribution of labeling in inferior olive and pontine nuclei indeed suggest that both RV and CTb label the same regions and potentially also the same neurons. This latter aspect was more specifically investigated by incubating selected series for fluorescent double labeling.

Figure 3 shows an example of fluorescent double labeling of $\mathrm{RV}$ (green) and CTb (red) in the contralateral inferior olive (Fig. 3A) and pontine nuclei (Fig. 3B) in case 1099 with a survival time of $48 \mathrm{~h}$. These and other examples show conclusively that the distribution of RV labeling is similar (and certainly not more extensive) to that of CTb-labeled cells in both the inferior olive and pontine nuclei. Moreover, many cells contain both labels (Fig. 3, arrows). However, it should also be noted that several neurons labeled for $\mathrm{RV}$ and intermingled with those labeled for $\mathrm{CTb}$ do not contain CTb label (Fig. 3, double arrowheads). We propose that these RV cells, at least partly, may reflect labeling by way of an alternative transneuronal but intracerebellar route that is not accessible to the CTb tracer. However, because these single RV-labeled cells, at least with a survival not in excess of $50 \mathrm{~h}$, were never seen outside of the distribution of CTb-labeled cells (see

\section{$\leftarrow$}

(Figure legend continued.) form the origin of climbing fibers to studied zones (shown in the same color) of the posterior cerebellum (right). Diagram was based on data provided by Voogd and Ruigrok (2004) (see also Atkins and Apps, 1997; Voogd et al., 2003; Pijpers and Ruigrok, 2006). Aud, Auditory cortex; $\beta, \beta$ subnucleus; $C g$, cingulate cortex; $C M A 0$, caudal MAO; DC, dorsal cap; dfDA0: dorsal fold of DA0; dIPO: dorsal leaf P0; DMCC, dorsomedial cell column; DMPO, dorsomedial group PO; Ent, entorhinal cortex; Front, frontal cortex (Fr3); iMA0, intermediate MA0; Ins, insular cortex; lat orb, lateral orbitofrontal cortex; M1, primary motor cortex; M2, premotor cortex; med orb, medial orbitofrontal cortex; Par, parietal cortex; Pir, piriform cortex; PM, paramedian lobule; P0, principal olive; Prelimb or prelimb, prelimbic cortex; rMAO, rostral MAO; RSC, retrosplenial cortex; $\mathrm{S} 1$, primary somatosensory cortex; $\mathrm{S} 2$, secondary somatosensory cortex; visual cortex; vfDAO, ventral fold of DAO; VLO, ventrolateral outgrowth; $v \mathrm{IPO}$, ventral leaf $\mathrm{PO}$. also Fig. 4), we suggest that they are labeled from the same functional cerebellar areas (Apps and Hawkes, 2009; Ruigrok, 2011).

Labeling in the cerebral cortex was never observed with CTband RV-labeled neurons were only observed after a survival of 50 and $70 \mathrm{~h}$ (Fig. 2A6,7-C6,7). Cases with a survival time of $50 \mathrm{~h}$ only demonstrated labeling of layer $\mathrm{V}$ pyramidal cells, without any labeling in other layers. In addition, no RV labeling within thalamic areas was noted. The three cases with a postinjection survival of $70 \mathrm{~h}$ all displayed intense labeling of layer $\mathrm{V}$ neurons, but additional labeling of many neurons in layers II-IV and VI was also apparent. In addition, many RV-infected small cells were found between the large pyramidal neurons of layer V. Furthermore, RV-labeled neurons were observed at various locations in the thalamus (data not shown). Based on these results, we conclude that a postinjection time of $30 \mathrm{~h}$ only labels first-order RV neurons whereas $50 \mathrm{~h}$ is sufficient time to allow robust secondorder labeling to occur without any sign of third-order labeling. On the other hand, $70 \mathrm{~h}$ clearly involves third-order, and potentially even fourth-order labeling. In all subsequent experiments, a survival time of $48-50 \mathrm{~h}$ was maintained to study the organization of the disynaptic cerebrocerebellar connection and only for these experiments the olivary, pontine and cortical labeling will be described below.

\section{Distribution of cerebral labeling relates to lobular and zonal determinants}

Lobule VIII injections

Figure 4 shows the results of 5 cases with injection of the RV/CTb solution in the copula of lobule VIII. Injections in the paravermal part result in pronounced labeling of both RV as well as $\mathrm{CTb}$ neurons in the lateral DAO in accordance with the dominant position of the C1-zone in this region of lobule VIII (compare Fig. 1 E; Atkins and Apps, 1997; Pijpers and Ruigrok, 2006). The climbing fibers of this region are known to specifically respond to stimulation of the ipsilateral hindlimb (Atkins and Apps, 1997). In addition, mossy fibers from hindlimb related areas are also known to project selectively to the hemisphere of lobule VIII (Pijpers and Ruigrok, 2006; Quy et al., 2011).

The injections in Figure 4 are ordered with increasing laterality. The olivary labeling responds by a diminishing contribution of labeling in the DAO and increasing incorporation of the lateral part of the intermediate MAO (compare Fig. 4 cases 1079, 1078, and 1101; for reference to olivary subnuclei, compare with Fig. $1 A, E)$. The intermediate MAO is known to supply climbing fibers to the CX zone, which is located lateral to the $\mathrm{C} 1$ zone (Voogd et al., 2003; Sugihara and Shinoda, 2004; Voogd and Ruigrok, 2004). Involvement of even more lateral areas of lobule VIII result in labeling of more rostral regions of the MAO, implying incorporation of the $\mathrm{C} 2$ zone, as well as labeling within the principal olive (PO), implying inclusion of the D-zone in the injection site. The response properties of the CX, C2 and D zones in lobule VIII of the rat have not been established unequivocally (Atkins and Apps, 1997).

Although the distribution of labeled neurons in the inferior olive varies markedly with respect to the laterality of the injection, the distribution of labeled RV and CTb-labeled neurons in the pontine nuclei is remarkably similar in all cases. In the BPN, most labeled neurons are positioned in a caudal shell which extends rostrally along the midline. In addition, there is a patch of labeled neurons located centrally in the rostral BPN. This pattern of labeling closely follows the description provided earlier by Pijpers and Ruigrok (2006). Labeling in the NRTP is mostly found in the lateral half of the contralateral side (Fig. 4D1-D5,E1-E5). Note 

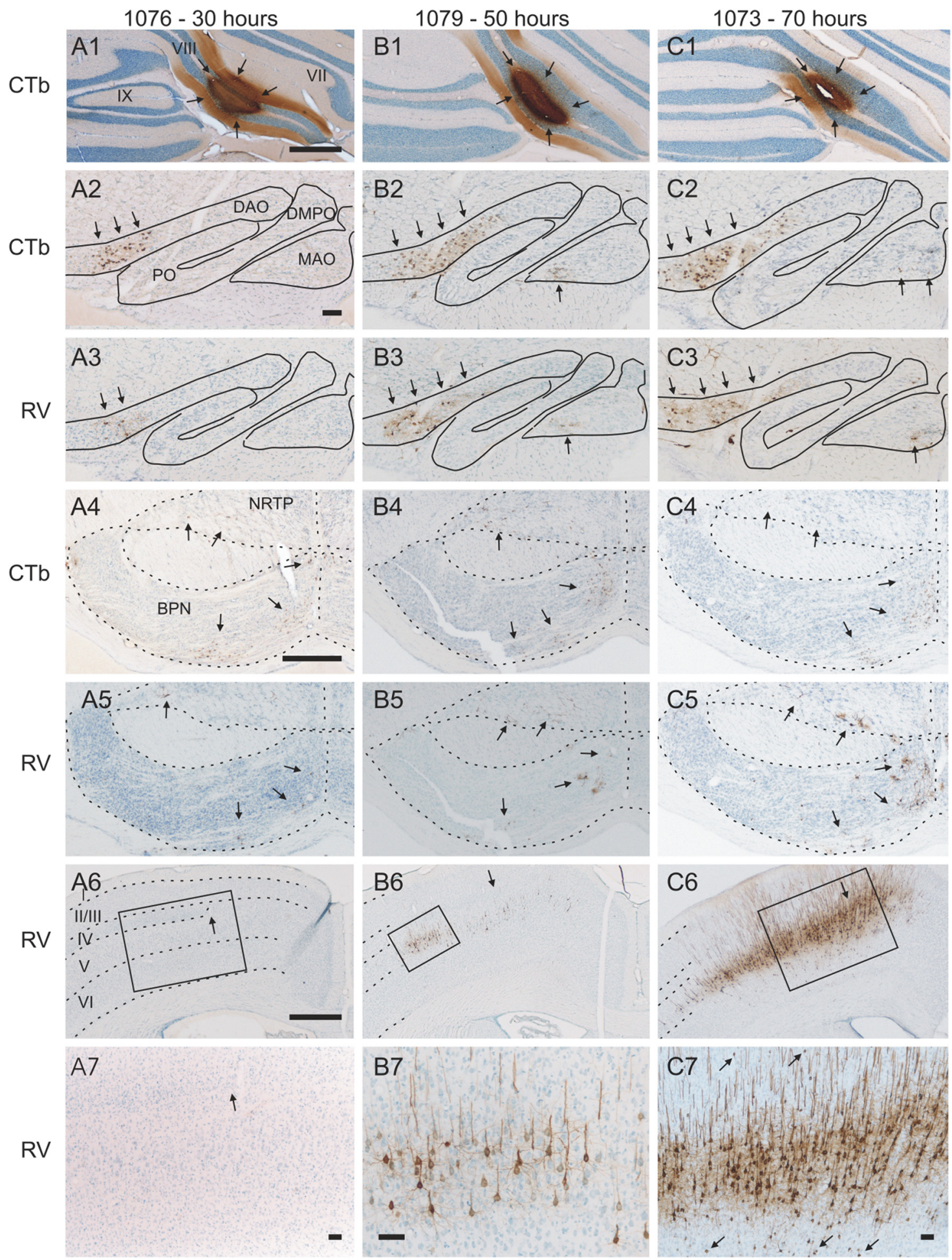

Figure 2. Microphotographs showing resultant labeling in three cases with an injection of RV centered on the paravermis of lobule VIII but with different survival times. A1-A7, Case 1076 with a survival time of $30 \mathrm{~h}$. The injection is shown by arrows in a section treated for (Tb immunohistochemistry ( $\boldsymbol{A} \mathbf{1})$. Retrogradely (Tb-labeled olivary cells are shown in $\boldsymbol{A 2}$ where they are predominantly found in the lateral half of the DAO (arrows). A3 shows an adjacent section immunoreacted against RV. A few infected cells are found at a similar position within the lateral DA0 (arrows). $\boldsymbol{A 4}, \boldsymbol{A 5}$, (Tb and RV labeling, respectively, within adjacent sections of the pontine nuclei. The position of the labeled neurons is approximately similar (arrows). A6, A7, Overview and detail, respectively, of an RV-immunoreacted section showing the medial cerebral cortex. At this survival time no RV labeling is observed. Arrows point to transition between granular and agranular cortex (also in $B \boldsymbol{6}$ and $\mathbf{C 6}$ ). $\mathbf{B 1}-\boldsymbol{B 7}$, similar to $\boldsymbol{A} \mathbf{1}-\mathbf{A 7}$ for case 1079 with a survival time of $50 \mathrm{~h}$. Note that location of $C$ Tb and RV labeling in inferior olive $(\boldsymbol{B 2}, \boldsymbol{B} 3)$ and pontine nuclei $(\boldsymbol{B 4}, \boldsymbol{B 5})$ is similar to case 1076 although now some labeled cells are also observed in the $\mathrm{MAO}$ (single arrow in $\mathbf{B 2}, \mathbf{B 3}$ ). $\mathbf{B}$ and $\mathbf{B 7}$ demonstrate layer $V$ labeling of pyramidal cells predominantly in medial granular cortex. $\mathbf{C 1}-\mathbf{C 7}$, Case 1073 with a survival time of $70 \mathrm{~h}$. C2 and C3 show CTb and RV labeling, respectively, at locations similar to that observed in cases 1076 and 1079 . C4 and C5 show CTb and RV labeling, respectively, in the pontine nuclei. Again, the distribution of the labeled cells is similar in all cases, although the number of RV-labeled neurons was increased. C6, C7, Overview and detail of the medial cerebral cortex. Note abundant labeling in multiple cortical layers (arrows). Also note the small somatic profiles within layer $V$ that are absent in $\boldsymbol{B}$. For abbreviations see Figure 1. Scale bars: $\boldsymbol{A} \mathbf{1}-\mathbf{C 1}$, $1000 \mu \mathrm{m}$; A2-C2, A3-C3, A7-C7, $100 \mu \mathrm{m} ; A 4-C 5,500 \mu \mathrm{m} ; A 6-C 6,1000 \mu \mathrm{m}$. 
that in cases with injections that mostly involve $\mathrm{C} 1$, virtually no ipsilateral labeling in the BPN was observed (Table 1), whereas involvement of the $\mathrm{C} 2$ - and $\mathrm{D}$-zones resulted in increased ipsilateral labeling (Pijpers et al., 2006).

The cortical labeling resulting from the lobule VIII injections is shown in Figure $4 F$. Figure $4 G$ shows the same flattened density profile of labeled layer $\mathrm{V}$ neurons but superimposed with a similarly constructed flattened representation of the functional cortical areas determined from the atlas of Paxinos and Watson (2005) (compare Fig. 1D). From these representations it is obvious that all lobule VIII injections result in a single dense patch of labeling that is found within the caudal aspects of the $\mathrm{M} 1, \mathrm{M} 2$, and $\mathrm{S} 1$ regions which represent the agranular primary motor and premotor cortices and the granular primary somatosensory cortex of the hindlimb, respectively (for review, see Palomero-Gallagher and Zilles, 2004). In addition, there is more sparse labeling within the $\mathrm{S} 2$ region and a separated patch of labeling more rostrally which could be localized to M2. The latter patch is not only more prominent in the cases with injection of the C2-D zones but also involves more conspicuous labeling of the same area at the contralateral side (see also Fig. 9).

On close inspection there are also some mediolateral differences to be noted in the main patch of labeling overlying the M1, M2 and S1 regions. Figure 4, $H$ and $I$, shows the summed mediolateral distribution within this patch of the five cases with injections in lobule VIII. Cases 1079, 1078, and 1101, with an injection that resulted in predominant labeling of the lateral DAO (i.e., involving $\mathrm{C} 1$ zone, but to some extent also CX: see Table 1), demonstrate a density peak around bin 14, which falls lateral to M1 within the medial part, i.e., hindlimb area, of S1. Cases 1075 and 1093, without labeling of the lateral DAO but involvement of MAO and PO (injection centered on C2-D zones; cf. Fig. $1 E$ ), display a density peak around bins 7 and 8 , which relates to the M2 and M1 regions. The conversion between agranular (M1) and granular (S1) cortex takes place around bin $10 / 11$.

\section{Lobule VII injections}

Three different regions of lobule VII received injections with the $\mathrm{RV} / \mathrm{CTb}$ mixture and will be described separately. Injections within the vermal region of lobule VII demonstrated a strikingly different pattern of cerebral labeling compared with the injections that were made in the paramedian lobule. In addition, the results from two injections that were made in crus IIb of lobule VII will be described.

Figure 5 shows the main results of three injections that were placed at progressively more lateral aspects in the vermis of lobule VII. The labeling pattern of all three cases, however, is rather similar, only showing quantitative differences. The distribution of CTb-labeled neurons in the inferior olive is virtually restricted to the medial part of the caudal MAO, mostly corresponding to group c (Ruigrok, 2004) with the more lateral injections resulting in a rostral shift of the labeling. The location of the olivary labeling confirms the location of the injection as A1-zone (Voogd and Ruigrok, 2004). In addition, all cases show some labeling within the caudal aspect of the ventral lamella of the PO (Fig. 5B1-B3, Table 1) as has been described by Sugihara and Shinoda (2004) (not indicated in the schematic diagram of Fig. $1 E$ ). CTb labeling of the pontine nuclei was abundant in all cases (Fig. 5C1-C3). Prominent labeling started caudally near the midline of the BPN as well as at its lateral aspect. Proceeding rostral-wards both labeled areas moved more centrally and joined at the rostral tip of the BPN. Despite the fact that the injection site did not invade the left side of the cerebellar cortex (as judged by the lack of ipsilaterally labeled olivary cells), there was a profound labeling within the ipsilateral BPN (also see Table 1). In a dorsal view of the density profile of the whole BPN this resulted in the appearance of an inverted 'W' for all three cases (Fig. 5C1-C3). Labeling in the NRTP was also bilateral with most labeled cells found near the rostral midline of the nucleus. The rather widespread and bilateral distribution of labeled CTb neurons in the pontine nuclei corresponded with a extensive bilateral distribution of RV-labeled pyramidal cells in the cerebral cortex (Fig. 5D1-D3,E1-E3). Cases 1123 and 1124 revealed three main areas of labeling. Intense labeling was found within the retrosplenial cortex, within a widespread area incorporating mostly somatosensory regions of S1, and, surprisingly, within the ventrolateral orbital cortex. The latter region 

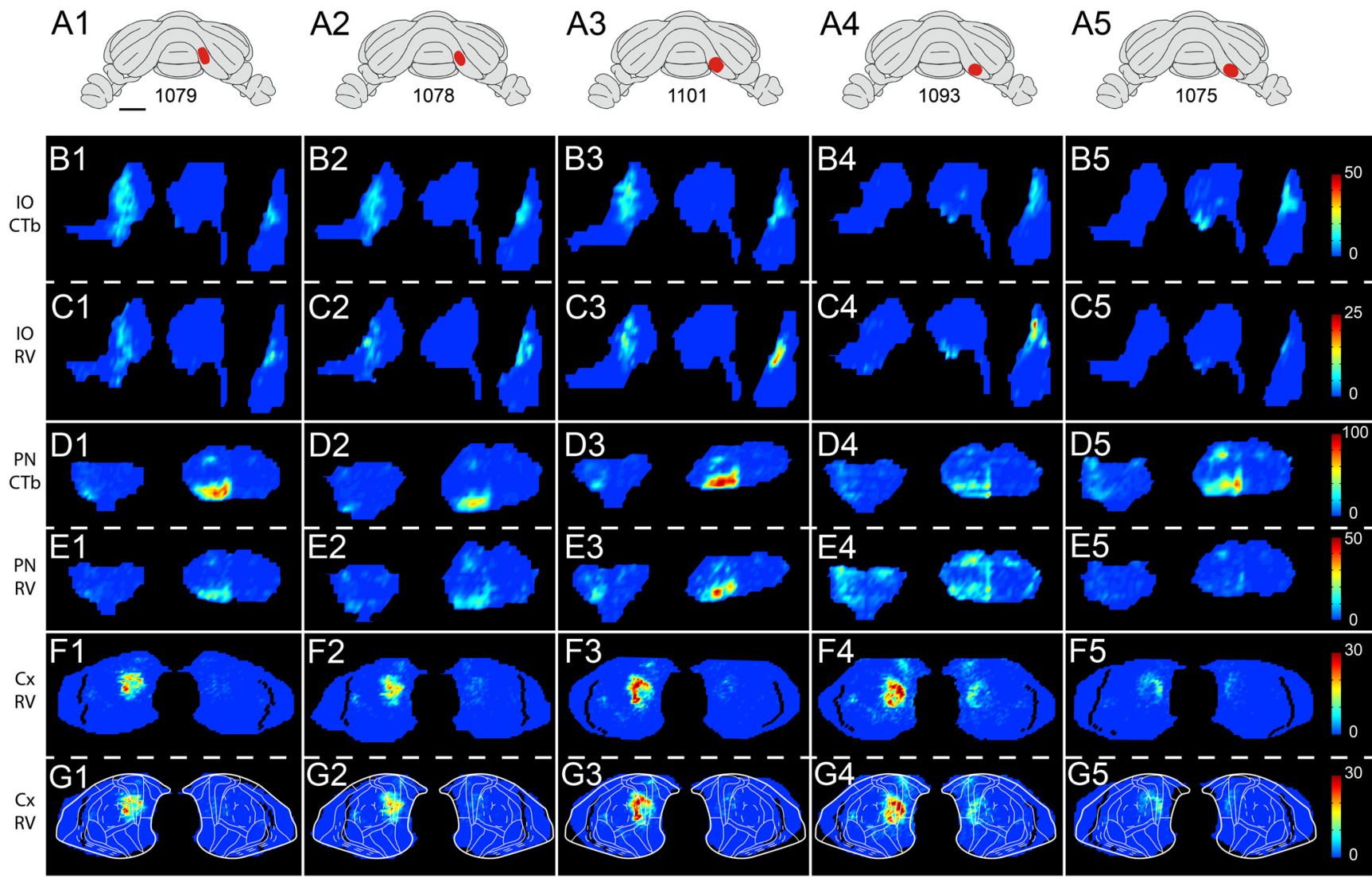

$\mathrm{H}$
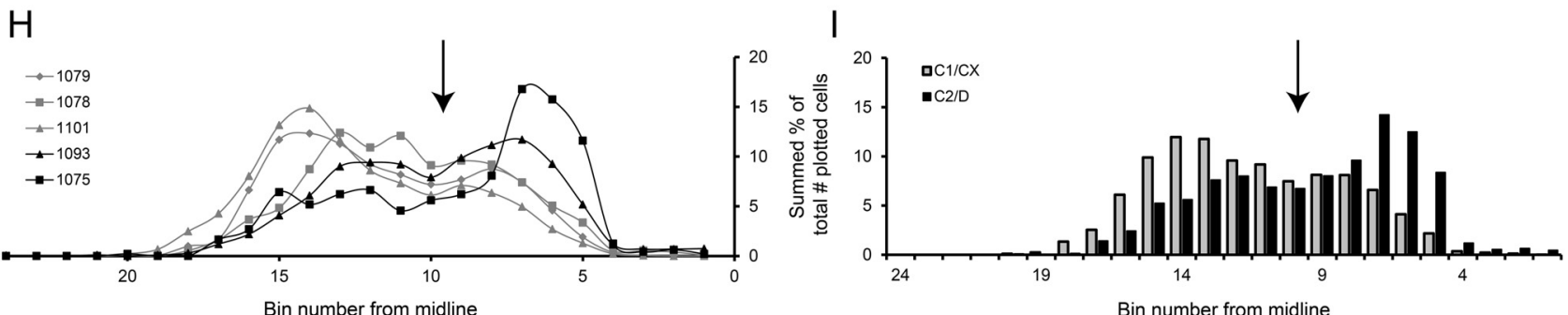

in number from midline

Figure 4. Distribution of CTb and RV labeling after injections in lobule VIII. Five different cases are illustrated, all with a survival time of 48 or $50 \mathrm{~h}$. A1-A5, Location and approximate size of the injection sites of the CTb/RV mixture based on CTb-incubated sections. The five cases are arranged from medial-most (A1) to lateral-most (A5). $\boldsymbol{B 1}$ - $\boldsymbol{B 5}$, Color-coded density plots of the left (contralateral) I0, prepared according to Figure 1A, and showing the distribution of (Tb-labeled cells. C1-C5, Similar plots of the inferior olive showing the distribution of RV-labeled cells. D1-D5, Color-coded density plots showing a dorsal view of the pontine nuclei (PN) with the left and right NRTP on the left side and the left and right BPN on the right side. For construction of plots, see Figure 1B. E1-E5, Similar plots showing distribution and density of RV labeling in the pontine nuclei. F1-F5, Color-coded density plots showing distribution of RV-labeled neurons in the cerebral cortex (Cx). Preparation of plots is explained in Figure 1C. G1-G5, Same as F1-F5 but superimposed with a similar map of the cerebral cortex. For construction and explanation of areas, see Figure 1D. $\boldsymbol{H}$, Mediolateral distribution of RV-labeled neurons contained in the main patch of labeling and shown for all five cases. The numbers of cells per bin are summed for all sections showing the main patch of labeling and are displayed as the percentage of the total number of labeled neurons. Two cases show a peak around bin $6-7$, whereas the other cases peak between bin 12 and 15 . Arrow indicates the transition between agranular and granular cortices. $\boldsymbol{I}$, Similar to $\boldsymbol{H}$, but averaged for the cases where the injection was centered on $C 1$ zone $(1078,1079$, and 1101$)$ and $C 2 / D$ zones $(1093$ and 1075). See Results, Lobule VIII injections for further explanation. For $\boldsymbol{B}-\mathbf{G}$ note that the color coding of the density varies (see color bars in $B 5-G 5)$. Scale bar $(A), 1 \mathrm{~mm}$.

even was the predominantly labeled area in case 1095, where the injection was restricted to the lateral part of the vermis.

Four injections made in the paramedian lobule and ordered from medial to lateral, are shown in Figure 6. In case 1126, CTblabeled olivary cells were noted in group b of the caudal MAO, in the caudal part of the rostral MAO and the medial part of the DAO (Fig. 6 B1). Based on this distribution the injection involved the A2-C1-CX and potentially C2 zones of the paramedian lobule (Apps and Hawkes, 2009). In zone A2, the lateral extension of the A zone (Voogd and Ruigrok, 2004) prominent climbing fiber responses are recorded when stimulating the contralateral face, whereas climbing fiber-evoked complex spikes in the C1 and C3 zones are triggered by ipsilateral and in the $\mathrm{C} 2$ zone by bilateral forelimb stimulation (Atkins and Apps, 1997). Mossy fibers supplying forelimb information to lobule VII have also been described (Pijpers and Ruigrok, 2006; Apps and Hawkes, 2009; Quy et al., 2011). Cases 1080 and 1125 mostly involved the paravermal regions $(\mathrm{C} 1-\mathrm{C} 3)$ as evidenced by the $\mathrm{CTb}$ labeling that was restricted to the medial DAO and rostral MAO (Fig. 6 B2,B3). Case 1127 resulted in labeling that was mostly limited to the dorsal lamella of the PO (Fig. 6 B4) and established the injection site to be within the D2-zone (Apps and Hawkes, 2009). Labeling in the pontine nuclei was essentially confined to an inverted " $\mathrm{V}$ "shaped region in the contralateral BPN (Fig. 6C1-C4). Ipsilateral labeling was present as a mirror image of the rostral aspect of the contralateral patch. This pattern of labeling was also described by 
A1

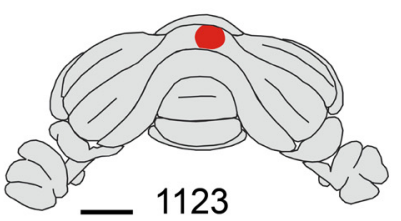

A2

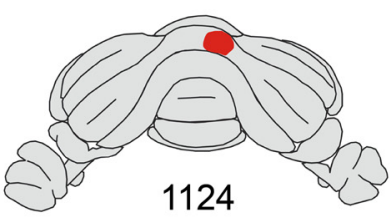

A3

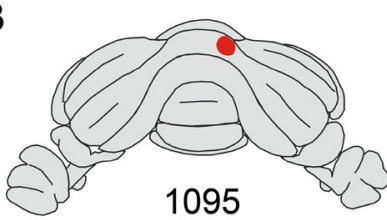

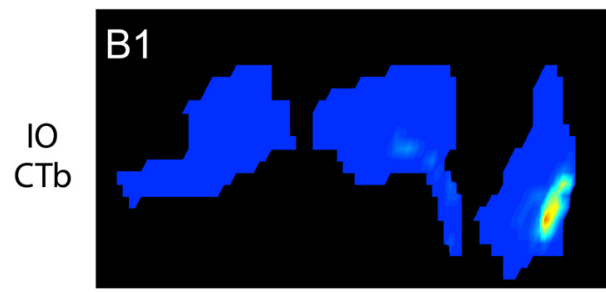
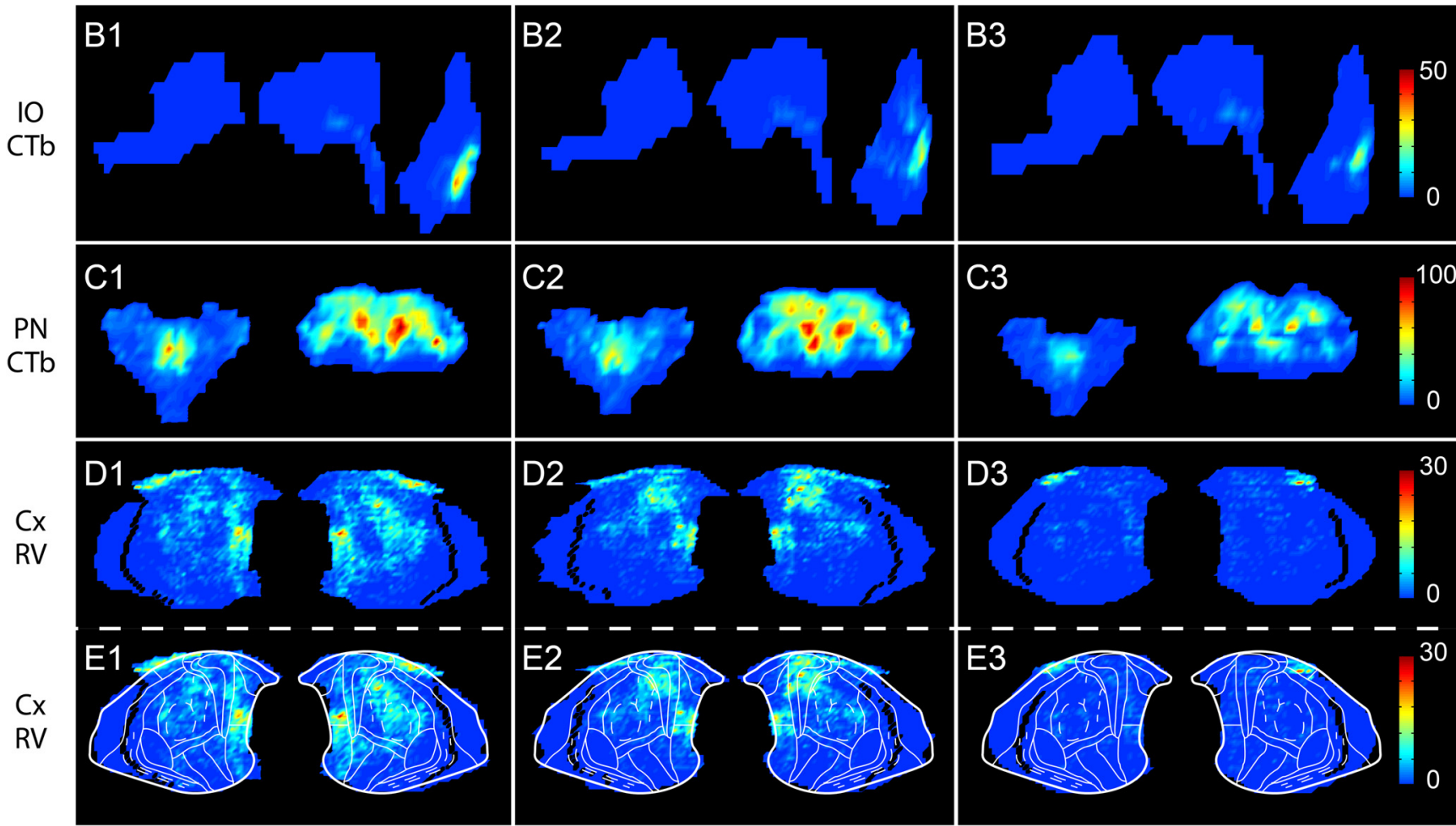

Figure 5. Labeling resulting from injections in the vermis of lobule VII. Three cases are shown, all with a survival time of $48 \mathrm{~h}$. $\mathbf{A 1}-\mathbf{A} \mathbf{3}$, Injection sites as determined from CTb-immunoreacted sections. Cases are ordered from the medial-most injection to the lateral-most. B1-B3, Density plots of CTb-labeled cells in the I0. Most cells are found in the medial part of the caudal MA0. C1-C3, Density plots of (Tb-labeled cells in the pontine nuclei (PN). Note wide distribution throughout NRTP and BPN and equal density in contra- and ipsilateral PN. D1-D3, Density plots of RV-labeled cells in the cerebral cortex (CX).E1-E3, Same density plots as D1-D3 but superimposed with the cortical map. See Results, Lobule VII injections for further explanation. Scale bar (A), $1 \mathrm{~mm}$. Note that color bars (B3-E3) are differently scaled.

Pijpers and Ruigrok (2006). NRTP labeling was specifically found in the central regions of the NRTP displaying a rather even bilateral distribution of labeled neurons (also see Table 1). As also seen in the cases with injections in lobule VIII, most labeled neurons in the cerebral cortex are located in a single patch, however, now this patch encompasses the $\mathrm{M} 1$ and $\mathrm{S} 1$ areas of the forelimb (Fig. 6D1-D3,E1-E3). This patch of labeling is located rostral and somewhat more lateral compared with the labeling observed after lobule VIII injections. The analyzed cases did not show a specific mediolateral distribution within this main patch of labeling as was noted in the cases with an injection in lobule VIII. We propose that this is related to the more complex and narrow zonal arrangement of the paramedian lobule (compare Fig. 1E). An additional, more rostromedially located, and smaller patch of labeling was observed within the confines of the rostral M2 region. This labeling was found lateral to that observed in the lobule VIII cases. A second smaller patch of labeling, especially conspicuous in the cases with the medial (case 1126)- and lateral-most (case 1127) injections, was located within the S2 region.

Finally, two injections involved the intermediate and lateral part of crus IIb and are shown in Figure 7. The medial injection (case 1098) resulted in CTb labeling that was localized in the rostromedial aspect of the DAO, the dorsmedial group (DMPO, compare Fig. $1 A$ ) and adjacent ventral lamella of the PO and within the rostral MAO (Fig. 7B1). The more lateral injection (case 1099) showed CTb-labeled neurons confined to the dorsal and ventral lamella (including DMPO). These patterns are consistent with involvement of both C and D zones in case 1098, whereas the injection was confined to the D-zone only in case 1099. Crus IIb has been shown to process climbing fiber signals from the ipsilateral face region (Pijpers and Ruigrok, 2006), which are likely to originate from the dorsomedial DAO (Gellman et al., 1983). In addition, mossy fiber input from many regions of the face to crus II has also been well documented (Apps and Hawkes, 2009; Bower, 2011). Pontine labeling was most prominently present in a single centrally localized patch within the contralateral BPN as described earlier (Leergaard et al., 2006; Pijpers and Ruigrok, 2006). A mirror image of this patch, which was especially prominent in case 1099) was found in the ipsilateral BPN (Fig. 7C1,C2). Cerebral RV labeling in these two cases was mainly found in the rostral-most regions of the dorsolateral cortex where they encompassed the rostral aspects of the M1 and M2 areas including frontal area 3 (Palomero-Gallagher and Zilles, 2004). Note that the involvement of C-zones in case 1098 resulted in a more prominent participation of the face region of the primary somatosensory cortex. Both injections also resulted in the labeling within S2. The selective involvement of the D-zone 
A1

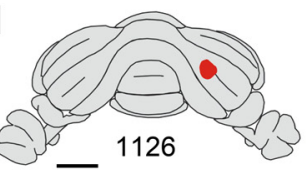

A2

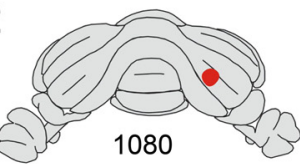

A3

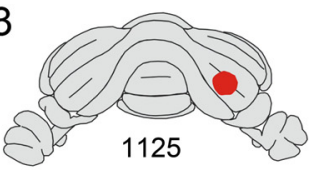

A4

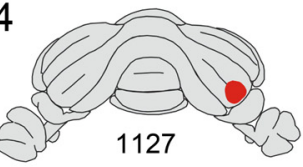

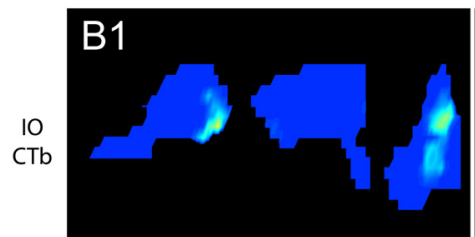
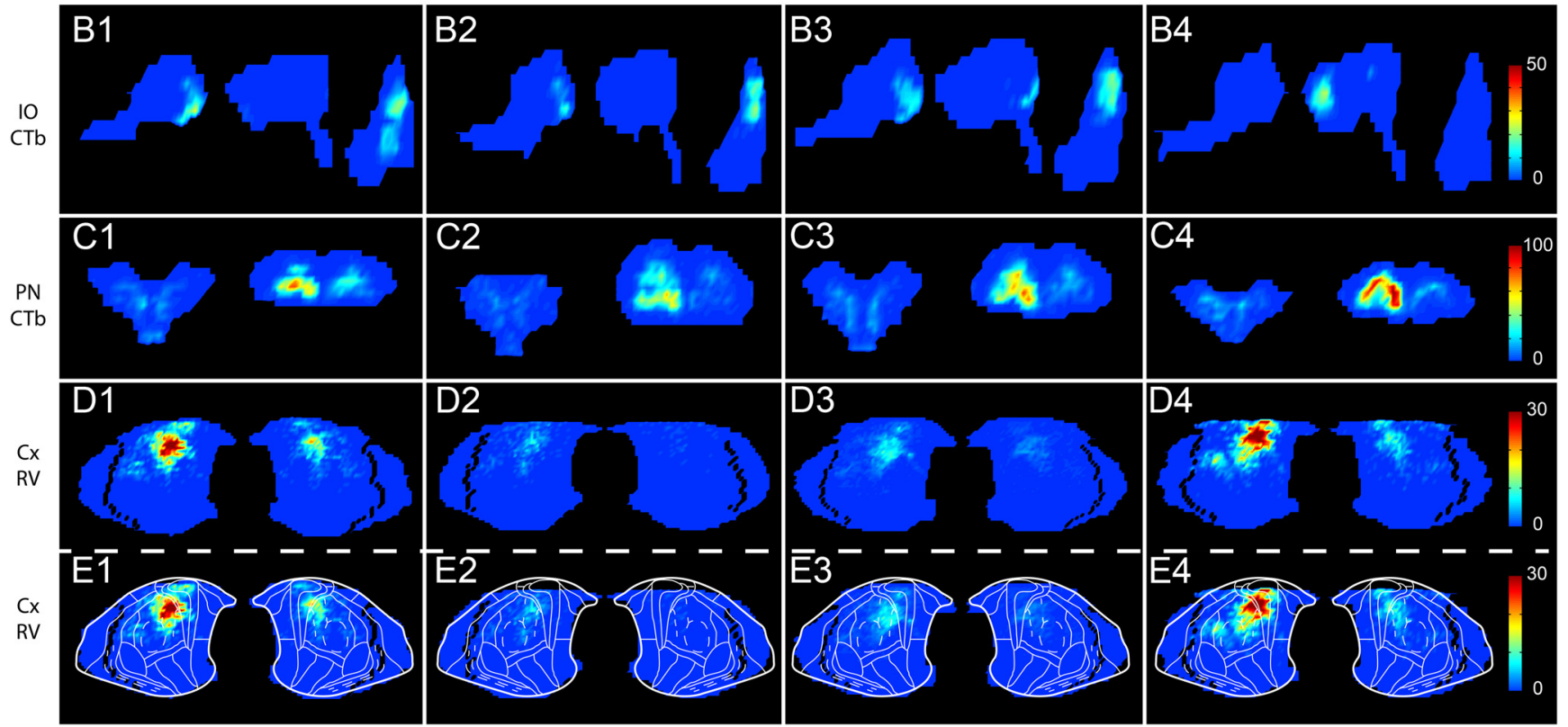

Figure 6. Labeling resulting from injections in the paramedian lobule. Four cases are shown, all with a survival time of 48 or $50 \mathrm{~h}$. $\mathbf{A 1 - A 4}$, Injections sites as determined from CTb-immunoreacted sections. Cases are ordered from the medial-most injection to the lateral-most. B1-B4, Density plots of (Tb-labeled cells in the I0. C1-C4, Density plots of CTb-labeled cells in the pontine nuclei (PN). D1-D4, Density plots of RV-labeled cells in the cerebral cortex (CX). E1-E4, Same density plots as D1-D4 but superimposed with the cortical map. See Results, Lobule VII injections for further explanation. Scale bar $(\boldsymbol{A}), 1 \mathrm{~mm}$. Note that color bars (B4-E4) are differently scaled.

in case 1099 corresponded with in a more conspicuous labeling of an ipsilateral mirror image in the cerebral cortex.

\section{General observations on the overall cerebrocerebellar organization}

From these results we conclude that aspects of the cerebrocerebellar organization adhere to both the lobular as well as to zonal aspects of the injection. The most obvious general observation concerns the fact that the respective paravermal and hemispheral parts of lobules VIII, VII, and crus IIb, mostly related to hindlimb, forelimb, and face, respectively, receive input from increasingly more rostrolaterally located areas of the cerebral cortex. This characteristic is clearly shown in Figure 8, which depicts a rendered $3 \mathrm{D}$-reconstruction based on the one of eight series of sequential cortical sections. Note that the main patch of labeling in the left side of the cortex shifts from a central to a more rostrolateral position when the injection site shifts from lobule VIII (case 1093), via paramedian lobule (case 1126) to crus IIb (case 1098).

This shift in labeling can also be appreciated in Figure 9, which shows diagrams of the caudorostral distribution of cortical RV labeling in both the contralateral (blue bars) as well as in the ipsilateral cortex (red bars) shown as the percentage/section of total plotted cortical cells. From these diagrams it can be appreciated that apart from already noted differences with respect to the lobular site of the injection also zonal differences can be appreciated. In lobule VIII, the contribution of ipsilateral labeling is much smaller when the injection was centered on the C1-zone compared with involvement of C2-D zones. However, the same observation cannot be made for the injections in the paramedian lobule. Here, the case that most selectively incorporated the $\mathrm{C} 2$ zone (case 1080) shows the least involvement of the ipsilateral cortex (Table 1). Ipsilateral involvement is even more conspicuous when the D-zone of crus IIb was targeted. The zonal differences related to lobule VIII injections resulting in differences with respect to the mediolateral position of RV-labeled cells has already been mentioned (Fig. $4 H, I$ ).

It is remarkable that the labeling observed after the vermal injections of lobule VII is completely different from that seen in all other cases (Fig. 8). Not only are labeled cells found in extremely wide areas of the cerebral cortex with particularly high densities in the retrosplenial and orbitofrontal cortices, they are also found in virtually identical numbers at both sides of the brain (Fig. 9).

\section{Verification of corticopontine projection map}

In a recently proposed hypothesis by Leergaard and Bjaalie (2007), based on a series of detailed studies on the corticopontine and pontocerebellar projections (Leergaard et al., 2000a,b, 2006; Bolstad et al., 2007), the organization of the corticopontine projection was explained by the interaction of two temporospatial gradients that determine growth and guidance of corticopontine fibers. One gradient concerns the neocortical maturation axis (Uylings et al., 1990), which follows concentric lines from the anterolateral cortex outwards and is transposed to an essentially inside-out axis of the BPN (Leergaard et al., 1995). The other gradient follows a frontal to occipital axis which translates to a mediolateral axis in the BPN (Wiesendanger and Wiesendanger, 1982). The combined influence of both gradients results in a complex transposition of the cerebral cortex onto the pontine nuclei which is visualized in Figure $10 \mathrm{~A}$ (modified from (Leergaard and Bjaalie, 2007), and that essentially predicts where corticopontine 
A1

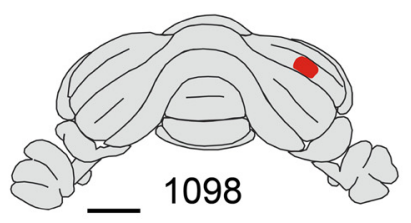

A2

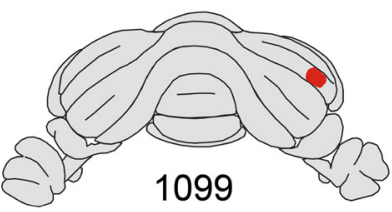

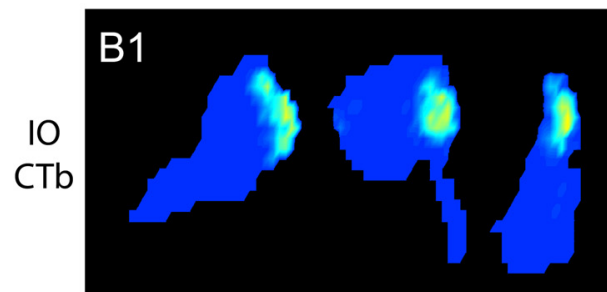
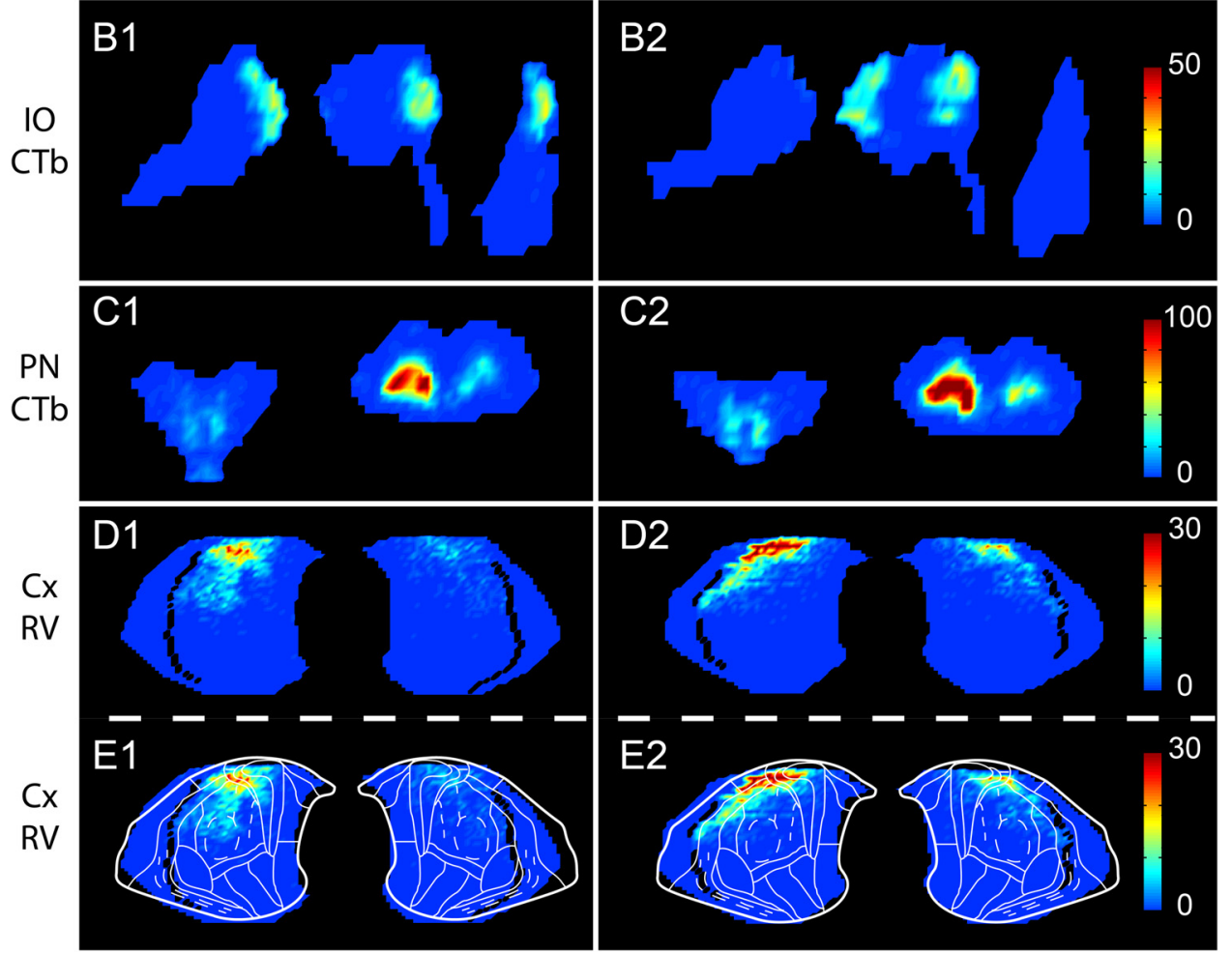

Figure 7. Labeling resulting from injections in crus Ilb. Two cases are shown each with a survival time of $48 \mathrm{~h}$. $\boldsymbol{A 1}, \mathbf{A 2}$, Injection sites as determined from CTb-immunoreacted sections. Cases are ordered from the medial-most injection to the lateral-most. B1, B2, Density plots of CTb-labeled cells in the I0. C1, C2, Density plots of (Tb-labeled cells in the pontine nuclei (PN). D1, D2, Density plots of RV-labeled cells in the cerebral cortex (Cx).E1, E2, Same density plots as D1 and D2 but superimposed with the cortical map. See Results, Lobule VII injections for further explanation. Scale $\operatorname{bar}(\boldsymbol{A}), 1 \mathrm{~mm}$. Note that color bars (B2-E2) are differently scaled.

Vermis

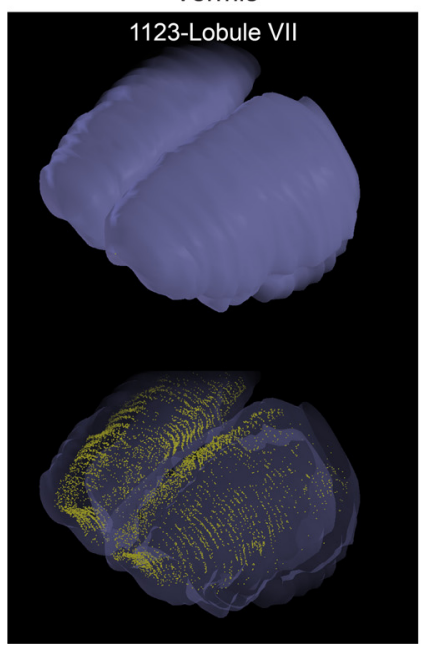

Hemisphere

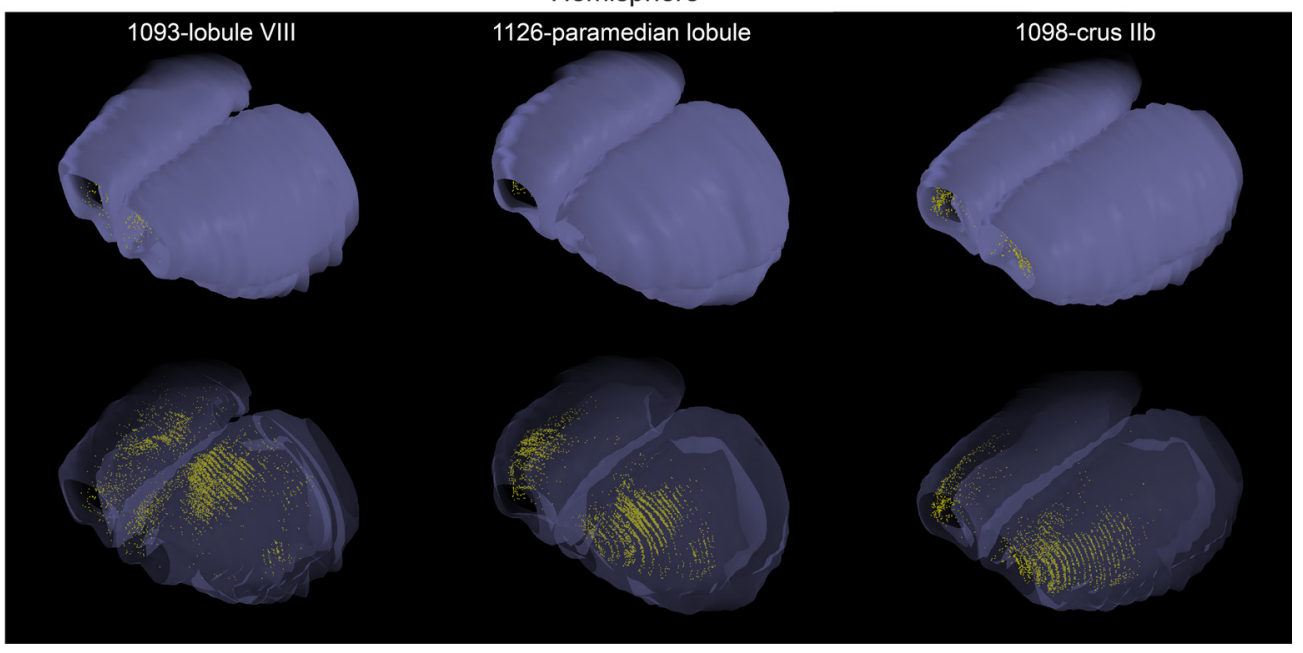

Figure 8. Three-dimensional reconstructions of the cerebral cortex. Four cases are shown from left to right: case 1123 with an injection in the vermis of lobule VII (Fig. 5A3), case 1093 with an injection in lobule VIII (Fig. 4A4), case 1126 with an injection in the paramedian lobule (Fig. 6A1), and case 1098 with an injection in crus llb (Fig. 7A1). Top depicts a solid rendering of the left and right cerebral cortex shown in a rostral dorsolateral view to be used for orientation purposes. In the bottom, the cortical surface rendering is made transparent to appreciate the distribution of RV-labeled neurons, which are shown as yellow dots. Reconstructions are based on a one of eight series of sections (see Material and Methods). See Results, General observations on the overall cerebrocerebellar organization for further explanation. 


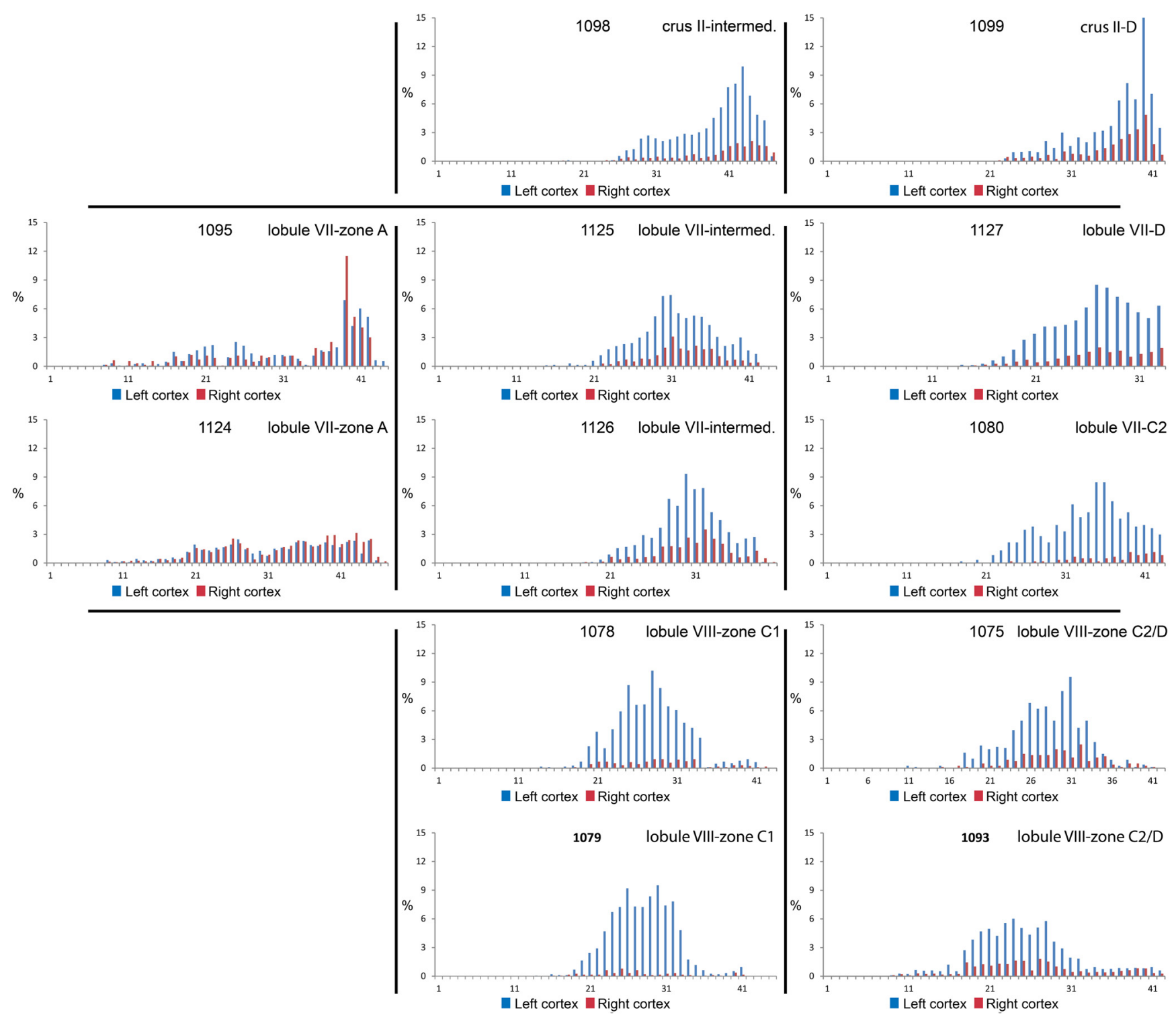

Figure 9. Caudorostral distribution of the number of RV-labeled neurons. RV-labeled neurons plotted at the contralateral (blue bars) and ipsilateral (red bars) side of the cerebral cortex are represented as the percentage of total RV-labeled cortical neurons. Each pair of bars represents a single plotted section of a one of eightseries of sections. Twelve selected cases are shown and are arranged with respect to the location of the injection (i.e., lobule VIII at bottom with lateral injections at the right). Note that the distribution is similar in cases with a similar injection site (cf. cases 1078 with 1079 and 1125 with 1126 ) but differs when the locations of the injection site vary. See Results, General observations on the overall cerebrocerebellar organization for further explanation.

terminals from a particular sector of the cerebral cortex are directed to. Based on the reverse of this transposition we have taken the actual positions of CTb-labeled neurons in the BPN and determined where in the cortex transneuronally RV-labeled corticopontine neurons are likely to be found (Fig. 10B). The density of cortical labeling was arbitrarily linked to the density of CTb labeling of the bins falling within the sectors determined by the model. The result of this reverse transposition subsequently can be compared with the actually observed distribution of RV-labeled cortical neurons (Fig. 10C). Because the model of Leergaard and Bjaalie is based on a dorsal view of the cortex, we composed a dorsal view of the cerebral cortex by removing the bins of the medial cortex that follows a vertical course toward the corpus callosum. The ventrolateral parts, not visible from a dorsal view were also removed and the width of the remaining bins was filtered using a horizontal mediolateral spherical distortion with Adobe Photoshop (CS3).

The results indicate that the corticopontine projection model generally predicts the distribution of the actually labeled cortical neurons quite accurately. Figure $10 C$ shows that the cortical labeling based on the position of pontine CTb labeling after lobule VIII injections (cases 1078 and 1075) is expected to be more caudal and medial than predicted after injections in the paramedian lobule (cases 1126 and 1127). These predictions nicely matched the actual distribution of labeled RV cells. However, the model did not show a clear distinction in the location of the expected labeling in cases 1098 and 1099 (crus IIb injections), which seems rather similar to that of the paramedian lobule cases, whereas the actually observed distribution is quite dissimilar. Also, apart from the main patch of labeling, the smaller regions of labeling overlying the rostral M2 region and the S2 area and that were seen in the lobule VIII and paramedian lobule cases did not show up using the model. In addition, the labeling after the vermal injections of lobule VII (case 1123), compares rather poorly with the expectations based on the model. Although the model does not deal with the ventral labeling seen in the orbitofrontal cortex, the actual labeling in the retrosplenial cortex is not predicted at all. On the other hand, due to the widespread presence 

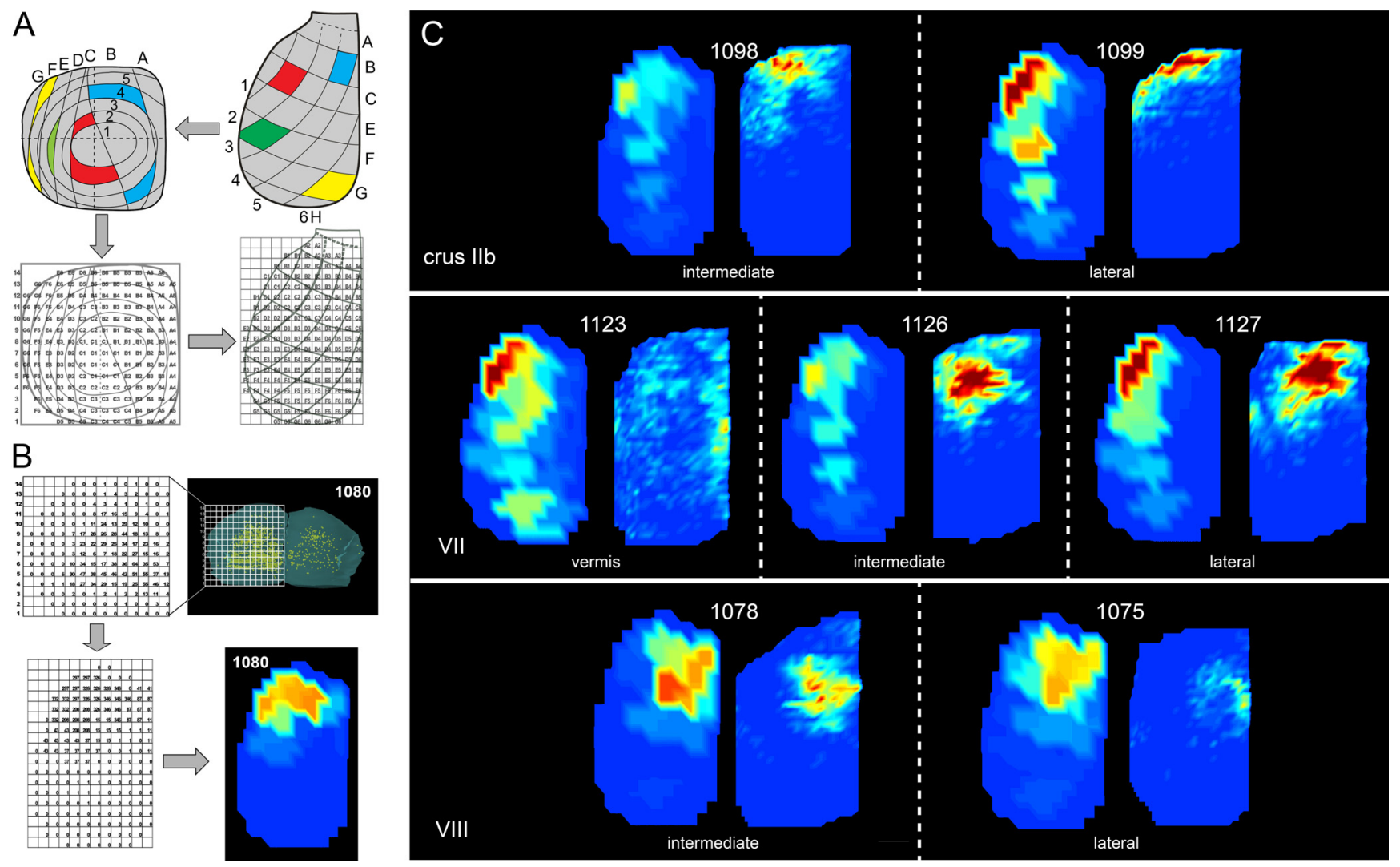

Figure 10. Comparing the distribution of corticopontine neurons predicted from the distribution and density of CTb-labeled neurons in the BPN and the actual distribution of RV labeling in the cerebral cortex. $A$, Model of corticopontine organization (top) modified from Leergaard and Bjaalie (2007). The dorsal views of the BPN and cortex are superimposed with grids with square gratings of 160 and $320 \mu \mathrm{m}$, respectively, on which the pontine and cortical density maps were based (Fig. 1B,C). B, Using the numbers of labeled neurons per grid, here shown for case 1080 , the numbers within analogous bins within the pontine grid are summed in the cortical grid and translated into a color-coded density plot. $C$, The predicted (left) and actual (right) distribution of RV-labeled neurons is shown for seven representative cases with injections in the investigated parts of the cerebellar cortex: i.e., lobule VIII (cases 1078 and 1075), vermis lobule VII (case 1123), paramedian lobule (cases 1126 and 1127), and crus Illb (cases 1098 and 1099). See Results, Verification of the corticopontine projection map for further explanation.

of CTb labeling in the BPN, the extensive labeling over the cortex seen in the model does resemble the actual distribution of RVlabeled neurons along a major part of the rostrocaudal axis of the cortex in this case.

Presently, it cannot be established whether the poor predictions concerning the patches of labeling in S2 and rostral motor area are due to the model or reflect the participation of extrapontine routes in the cerebrocerebellar communication. Nevertheless, especially in the case of the vermal injections where the retrosplenial and orbitofrontal labeling was not expected in the model, yet a prominent pontine involvement was present, an adaption of the model may be suggested.

\section{Discussion}

This study shows that the origin of disynaptic cerebrocerebellar projections to different lobules and zones in the posterior cerebellum of the rat studied with RV depends mainly on the identity of the injected lobule. More subtle changes are noted with respect to the zonal identity of the injected lobule. Cortical input to the vermis of lobule VII differs significantly from that to the other injected areas.

\section{Methodological issues: uptake of RV and CTb}

Using the RV/CTb mixture enabled evaluation of the location and spread of the injection site (Ugolini, 2010). Based on the numbers of CTb-labeled neurons in cases with different survival times (Table 1), we conclude that CTb does not disperse signifi- cantly over time and enables accurate determination of the zonal location(s) of the injection site.

In the single case with a survival of $30 \mathrm{~h}$, only a modest amount of precerebellar neurons was labeled with RV ( 55 in the IO and 235 in the pontine nuclei), whereas $\sim 7$ times this number labeled with $\mathrm{CTb}$ (Table 1 ). This suggests that RV infects only a minority of cells within a specific injection area. Moreover, it was surprising to see that increasing the survival time to $50 \mathrm{~h}$, which allowed infection of second order olivary neurons, did not change their distribution as it still fell completely within that of the CTblabeled neurons (compare Fig. 4). Alternative routes for secondorder olivary labeling would not only apply to that by way of first-order infected Purkinje cells within and around the injection site, but could also involve climbing fiber collaterals to the cerebellar nuclei where first-order nucleo-cortical neurons are labeled (Batini et al., 1992; Ruigrok and Voogd, 2000). Because the nucleo-cortical organization is partly nonreciprocal and also includes contralateral connections (Buisseret-Delmas and Angaut, 1989), the observation that at $50 \mathrm{~h}$ all RV labeling was restricted to the areas with $\mathrm{CTb}$ labeling and no RV labeling was observed in the ipsilateral olive suggests that RV infection by way of the nuclear collaterals of climbing fibers is not a prominent route (Ruigrok et al., 2008).

\section{Role of extra-pontine routes}

Pathways other than the cerebro-ponto-cerebellar route may be involved in disynaptic cerebrocerebellar communication. In- 
deed, various sources of mossy fibers, such as the dorsal column nuclei, trigeminal nuclei, lateral reticular nucleus and paramedian reticular formation have been reported to receive cortical input (Allen and Tsukahara, 1974; Lee and Kim, 2012). Although CTb-labeled cells were noted in many of these areas, their full analysis fell outside the scope of the present study. Moreover, the disynaptic nature of these extra-pontine routes has not yet been firmly established. Also, no information is available concerning to what extent pontine and extra-pontine routes mediate distinct information or reflect a different functional organization. This is particularly interesting with respect to the special role served by the cerebro-olivo-cerebellar pathways. For example, it seems remarkable that climbing fiber responses in vermal lobule VII may be triggered from the prelimbic cortex (Watson et al., 2009) which does not qualify as a major disynaptic source to this region. Of course, although to some extent the cerebro-olivo-cerebellar pathway is disynaptic (Lee and Kim, 2012), it usually involves more synapses (Baker et al., 2001; Pardoe et al., 2004).

\section{Specific cerebral input to lobules and zones}

The distribution of disynaptic cortical RV labeling was most clearly related to the identity of the injected cerebellar lobule. The location of the main patch of infected pyramidal cells after injections of paravermis and hemisphere of lobule VIII approximated the caudal regions of M1, M2 and S1 of the hindlimb (Paxinos and Watson, 2005). The similarity in general labeling pattern was mimicked by a comparable distribution of CTb-labeled neurons in the BPN. However, as expected, the inferior olive showed quite distinct labeling patterns related to the zonal identity of the injection. From this it could be surmised that the different $C$ and $D$ zones of lobule VIII (Atkins and Apps, 1997; Voogd et al., 2003) essentially receive the same information from the cerebral cortex. Yet, we also noted that the density of RV-labeled neurons within $\mathrm{S} 1$ was higher when the injection covered $\mathrm{C} 1$, whereas it was more pronounced in the motor areas when the injection was centered on C2 (and D). Neurons in the lateral DAO (projecting to C1) respond to touch or painful cutaneous stimulation of the contralateral hindlimb whereas many neurons of the rostral MAO (supplying climbing fibers to the $\mathrm{C} 2$ zone) have bilateral receptive fields and often respond to proprioceptive stimulation (Gellman et al., 1985; Garwicz et al., 1992; Atkins and Apps, 1997). The somatosensory nature of the $\mathrm{C} 1$ zone seems to be reciprocated by a dominant input from the S1 hindlimb region whereas the cerebral input to $\mathrm{C} 2$ is mostly derived from (pre)motor regions.

The main patch of RV labeling after paramedian injections was found rostral to that of the lobule VIII injections within the $\mathrm{M} 1, \mathrm{M} 2$ regions and the adjacent $\mathrm{S} 1$ forelimb region (Paxinos and Watson, 2005). Here also, although different cases displayed similar distributions of cortical RV labeling as well as of pontine $\mathrm{CTb}$ labeling, CTb distribution within the inferior olive differed. Because it was not possible to target a single paramedian zone an observation similar to that for lobule VIII injections, where distinct $\mathrm{RV}$ densities correlated with $\mathrm{C} 1$ or $\mathrm{C} 2 / \mathrm{D}$ identity, could not be made. Nevertheless, because mossy fibers terminating within adjacent zones display distinct collateralization patterns (Voogd et al., 2003; Pijpers et al., 2006), we suspect that similar differences may still exist. The main patch of cortical input to the paramedian D2 zone (case 1127) was shifted even further rostrally to include a larger aspect of M1 and M2 implying (as for the $\mathrm{C} 2 / \mathrm{D}$ zones of lobule VIII) a more prominent input from the (pre)motor cortex (compare Fig. 6E1,E4). Zonal differences in cerebrocerebellar connectivity without matching differences in distribution of pontine labeling suggest that pontine cells that project to different cerebellar zones may be intermingled (Pijpers et al., 2006).

Injections in crus IIb resulted in labeling within the face region of S1. This is in accordance with the receptive fields that can be recorded in the granular layer (Welker, 1987), but also with receptive climbing fiber fields (Pijpers and Ruigrok, 2006). However, especially when the D-zone was involved in the injection site, the most prominent cerebrocerebellar input is derived from the rostral motor and premotor cortex.

The hotspots of RV labeling after the vermal injections of lobule VII (i.e., the retrosplenial and orbitofrontal cortices) were unexpected. Vermal lobule VII is frequently associated with saccades (Godschalk et al., 1994; Voogd and Barmack, 2006) suggesting potential RV labeling of the frontal eye field, located in the medial frontal cortex, and posterior visual areas (Torigoe et al., 1986; Guandalini, 2001; Voogd et al., 2012). However, although some labeling was observed in these areas (Fig. 5E3), most labeling was distributed elsewhere. The dense labeling within the orbitofrontal and retrosplenial cortices suggest cerebellar impact on functions related to choice-making behavior (Mar et al., 2011) and performance in spatial learning tasks (St-Laurent et al., 2009), respectively. Indeed, such functions would be more in line with several emotional and attentional syndromes that have been associated with the posterior vermis in both animals and man (Holroyd et al., 1991; Caston et al., 1998; Bobée et al., 2000; Joyal et al., 2004). Labeling within the anterior cingulate cortex was recently also reported in a preliminary study after RV injections into the vermis of lobules V and VI and was suggested to be involved in fear learning (Galgiani et al., 2011).

\section{Bilateral labeling}

The ipsilateral contribution of cerebrocerebellar connections correlated nicely with the laterality of the CTb labeling in the pontine nuclei suggesting that this ipsilateral connection predominantly stems from the bilateral projection of the pontine nuclei to the cerebellar cortex (Serapide et al., 2002) rather than from a bilateral corticopontine projection (Legg et al., 1989; Leergaard et al., 2000b). Although the ipsilateral distribution of cortical RV labeling was similar to that observed contralaterally, local differences in density were observed; e.g., the density of the rostral M1/M2 patch was usually increased with respect to the ipsilateral main patch of labeling (Fig. 9). In addition, the laterality of the labeling was different when different zones were incorporated within the injection. Whereas injection of $\mathrm{Cl}$ of lobule VIII (hindlimb) hardly resulted in ipsilateral cortical labeling, C2 produced up to $30 \%$ (Table 1). This situation was reversed for the paramedian lobule where injections centered on the forelimb part of $\mathrm{C} 1$ resulted in rather prominent ipsilateral cortical labeling. This difference, also reflected by laterality differences of CTb labeling within the pontine nuclei (Pijpers and Ruigrok, 2006) may relate to different functional use of hind and forelimbs. A prominent ipsilateral cerebrocerebellar contribution was also noted to the D-zone of crus IIb. Bilaterality of the cerebrocerebellar connections, however, was most prominent after the vermal injections of lobule VII.

We conclude that that the distinct bilateral input to different lobules/zones reflect different functional properties of these cerebellar areas (Ruigrok et al., 2008).

\section{References}

Allen GI, Tsukahara N (1974) Cerebrocerebellar communication system. Physiol Rev 54:957-1006.

Apps R, Garwicz M (2005) Anatomical and physiological foundations of cerebellar information processing. Nat Rev Neurosci 6:297-311. 
Apps R, Hawkes R (2009) Cerebellar cortical organization: a one-map hypothesis. Nat Rev Neurosci 10:670-681.

Atkins MJ, Apps R (1997) Somatotopical organisation within the climbing fibre projection to the paramedian lobule and copula pyramidis of the rat cerebellum. J Comp Neurol 389:249-263.

Baker MR, Javid M, Edgley SA (2001) Activation of cerebellar climbing fibres to rat cerebellar posterior lobe from motor cortical output pathways. J Physiol 536:825-839.

Batini C, Compoint C, Buisseret-Delmas C, Daniel H, Guegan M (1992) Cerebellar nuclei and the nucleocortical projections in the rat: retrograde tracing coupled to GABA and glutamate immunohistochemistry. J Comp Neurol 315:74-84.

Bobée S, Mariette E, Tremblay-Leveau H, Caston J (2000) Effects of early midline cerebellar lesion on cognitive and emotional functions in the rat. Behav Brain Res 112:107-117.

Bolstad I, Leergaard TB, Bjaalie JG (2007) Branching of individual somatosensory cerebropontine axons in rat: evidence of divergence. Brain Struct Funct 212:85-93.

Bower JM (2011) Functional implications of tactile projection patterns to the lateral hemispheres of the cerebellum of the albino rat: the legacy of Wally Welker. Ann N Y Acad Sci 1225:130-141.

Buisseret-Delmas C, Angaut P (1989) Anatomical mapping of the cerebellar nucleo-cortical projections in the rat: a retrograde labeling study. J Comp Neurol 288:297-310.

Caston J, Yon E, Mellier D, Godfrey HP, Delhaye-bouchaud N, Mariani J (1998) An animal model of autism: behavioural studies in the GS guineapig. Eur J Neurosci 10:2677-2684.

Chen S, Aston-Jones G (1995) Evidence that cholera toxin B subunit (CTb) can be avidly taken up and transported by fibers of passage. Brain Res 674:107-111.

Coulon P, Bras H, Vinay L (2011) Characterization of last-order premotor interneurons by transneuronal tracing with rabies virus in the neonatal mouse spinal cord. J Comp Neurol 519:3470-3487.

Galgiani JE, Billig I, Strick PL (2011) Regions of the cerebellar vermis are the target of input from multiple cortical areas. Soc Neurosci Abstr $38: 101.108$

Garwicz M, Ekerot CF, Schouenborg J (1992) Distribution of cutaneous nociceptive and tactile climbing fibre input to sagittal zones in cat cerebellar anterior lobe. Eur J Neurosci 4:289-295.

Gellman R, Houk JC, Gibson AR (1983) Somatosensory properties of the inferior olive of the cat. J Comp Neurol 215:228-243.

Gellman R, Gibson AR, Houk JC (1985) Inferior olivary neurons in the awake cat: detection of contact and passive body displacement. J Neurophysiol 54:40-60.

Godschalk M, Van der Burg J, Van Duin B, De Zeeuw CI (1994) Topography of saccadic eye movements evoked by microstimulation in rabbit cerebellar vermis. J Physiol 480:147-153.

Guandalini P (2001) The efferent connections to the thalamus and brainstem of the physiologically defined eye field in the rat medial frontal cortex. Brain Res Bull 54:175-186.

Holroyd S, Reiss AL, Bryan RN (1991) Autistic features in Joubert syndrome: a genetic disorder with agenesis of the cerebellar vermis. Biol Psychiatry 29:287-294.

Joyal CC, Pennanen C, Tiihonen E, Laakso MP, Tiihonen J, Aronen HJ (2004) MRI volumetry of the vermis and the cerebellar hemispheres in men with schizophrenia. Psychiatry Res 131:115-124.

Kelly RM, Strick PL (2000) Rabies as a transneuronal tracer of circuits in the central nervous system. J Neurosci Methods 103:63-71.

Lee T, Kim U (2012) Descending projections from the dysgranular zone of rat primary somatosensory cortex processing deep somatic input. J Comp Neurol 520:1021-1046.

Leergaard TB, Bjaalie JG (2007) Topography of the complete corticopontine projection: from experiments to principal Maps. Front Neurosci $1: 211-223$.

Leergaard TB, Lakke EA, Bjaalie JG (1995) Topographical organization in the early postnatal corticopontine projection: a carbocyanine dye and 3-D computer reconstruction study in the rat. J Comp Neurol 361:77-94.

Leergaard TB, Lyngstad KA, Thompson JH, Taeymans S, Vos BP, De Schutter E, Bower JM, Bjaalie JG (2000a) Rat somatosensory cerebropontocerebellar pathways: spatial relationships of the somatotopic map of the primary somatosensory cortex are preserved in a three-dimensional clustered pontine map. J Comp Neurol 422:246-266.
Leergaard TB, Alloway KD, Mutic JJ, Bjaalie JG (2000b) Three-dimensional topography of corticopontine projections from rat barrel cortex: correlations with corticostriatal organization. J Neurosci 20:8474-8484.

Leergaard TB, Lillehaug S, De Schutter E, Bower JM, Bjaalie JG (2006) Topographical organization of pathways from somatosensory cortex through the pontine nuclei to tactile regions of the rat cerebellar hemispheres. Eur J Neurosci 24:2801-2812.

Legg CR, Mercier B, Glickstein M (1989) Corticopontine projection in the rat: the distribution of labelled cortical cells after large injections of horseradish peroxidase in the pontine nuclei. J Comp Neurol 286:427-441.

Mar AC, Walker AL, Theobald DE, Eagle DM, Robbins TW (2011) Dissociable effects of lesions to orbitofrontal cortex subregions on impulsive choice in the rat. J Neurosci 31:6398-6404.

Odeh F, Ackerley R, Bjaalie JG, Apps R (2005) Pontine maps linking somatosensory and cerebellar cortices are in register with climbing fiber somatotopy. J Neurosci 25:5680-5690.

Palomero-Gallagher N, Zilles K (2004) Isocortex. In: The rat nervous system, Ed 3 (Paxinos G, ed), pp 729-757. San Diego: Elsevier Academic.

Pardoe J, Edgley SA, Drew T, Apps R (2004) Changes in excitability of ascending and descending inputs to cerebellar climbing fibers during locomotion. J Neurosci 24:2656-2666.

Paxinos G, Watson C (2005) The rat brain in stereotaxic coordinates, Ed 5. San Diego: Elsevier Academic.

Pijpers A, Ruigrok TJ (2006) Organization of pontocerebellar projections to identified climbing fiber zones in the rat. J Comp Neurol 496:513-528.

Pijpers A, Voogd J, Ruigrok TJ (2005) Topography of olivo-cortico-nuclear modules in the intermediate cerebellum of the rat. J Comp Neurol 492:193-213.

Pijpers A, Apps R, Pardoe J, Voogd J, Ruigrok TJ (2006) Precise spatial relationships between mossy fibers and climbing fibers in rat cerebellar cortical zones. J Neurosci 26:12067-12080.

Pijpers A, Winkelman BH, Bronsing R, Ruigrok TJ (2008) Selective impairment of the cerebellar $\mathrm{C} 1$ module involved in rat hind limb control reduces step-dependent modulation of cutaneous reflexes. J Neurosci 28:2179-2189.

Prevosto V, Graf W, Ugolini G (2009) Posterior parietal cortex areas MIP and LIPv receive eye position and velocity inputs via ascending prepositothalamo-cortical pathways. Eur J Neurosci 30:1151-1161.

Quy PN, Fujita H, Sakamoto Y, Na J, Sugihara I (2011) Projection patterns of single mossy fiber axons originating from the dorsal column nuclei mapped on the aldolase $\mathrm{C}$ compartments in the rat cerebellar cortex. J Comp Neurol 519:874-899.

Raux H, Iseni F, Lafay F, Blondel D (1997) Mapping of monoclonal antibody epitopes of the rabies virus P protein. J Gen Virol 78:119-124.

Ruigrok TJ (2003) Collateralization of climbing and mossy fibers projecting to the nodulus and flocculus of the rat cerebellum. J Comp Neurol 466:278-298.

Ruigrok TJ (2011) Ins and outs of cerebellar modules. Cerebellum 10:464-474.

Ruigrok TJ, Voogd J (2000) Organization of projections from the inferior olive to the cerebellar nuclei in the rat. J Comp Neurol 426:209-228.

Ruigrok TJ, Pijpers A, Goedknegt-Sabel E, Coulon P (2008) Multiple cerebellar zones are involved in the control of individual muscles: a retrograde transneuronal tracing study with rabies virus in the rat. Eur J Neurosci 28:181-200.

Ruigrok TJH (2004) Precerebellar nuclei and red nucleus. In: The rat nervous system, Ed 3 (Paxinos G, ed), pp 167-204. San Diego: Elsevier Academic.

Salin P, Castle M, Kachidian P, Barroso-Chinea P, López IP, Rico AJ, Kerkerian-Le Goff L, Coulon P, Lanciego JL (2008) High-resolution neuroanatomical tract-tracing for the analysis of striatal microcircuits. Brain Res 1221:49-58.

Salin P, López IP, Kachidian P, Barroso-Chinea P, Rico AJ, Gómez-Bautista V, Coulon P, Kerkerian-Le Goff L, Lanciego JL (2009) Changes to interneuron-driven striatal microcircuits in a rat model of Parkinson's disease. Neurobiol Dis 34:545-552.

Schmahmann JD, Caplan D (2006) Cognition, emotion and the cerebellum. Brain 129:290-292.

Schmahmann JD, Sherman JC (1998) The cerebellar cognitive affective syndrome. Brain 121:561-579.

Serapide MF, Zappalà A, Parenti R, Pantò MR, Cicirata F (2002) Later- 
ality of the pontocerebellar projections in the rat. Eur J Neurosci 15:1551-1556.

St-Laurent M, Petrides M, Sziklas V (2009) Does the cingulate cortex contribute to spatial conditional associative learning in the rat? Hippocampus 19:612-622.

Strick PL, Dum RP, Fiez JA (2009) Cerebellum and nonmotor function. Annu Rev Neurosci 32:413-434.

Sugihara I, Shinoda Y (2004) Molecular, topographic, and functional organization of the cerebellar cortex: a study with combined aldolase $\mathrm{C}$ and olivocerebellar labeling. J Neurosci 24:8771-8785.

Suzuki L, Coulon P, Ruigrok TJH (2010) Organization of cerebral projections to identified cerebellar zones as studied by transneuronal transport of rabies virus in the rat. In: 7th FENS Forum meeting, $\mathrm{p}$ 141.115. Amsterdam.

Teune TM, van der Burg J, van der Moer J, Voogd J, Ruigrok TJH (2000) Topography of cerebellar nuclear projections to the brain stem in the rat. In: Cerebellar modules: molecules, morphology and function (Gerrits NM, Ruigrok TJH, De Zeeuw CI, eds), pp 141-172. Amsterdam: Elsevier Science B.V.

Torigoe Y, Blanks RHI, Precht W (1986) Anatomical studies on the nucleus reticularis tegmenti pontis in the rat. I. Cytoarchitecture, topography, and cerebral cortical afferents. J Comp Neurol 243:71-87.

Ugolini G (1995) Specificity of rabies virus as a transneuronal tracer of motor networks: Transfer from hypoglossal motoneurons to connected second-order and higher order central nervous system cell groups. J Comp Neurol 356:457-480.

Ugolini G (2010) Advances in viral transneuronal tracing. J Neurosci Methods 194:2-20.

Ugolini G, Klam F, Doldan Dans M, Dubayle D, Brandi AM, Büttner-Ennever J, Graf W (2006) Horizontal eye movement networks in primates as revealed by retrograde transneuronal transfer of rabies virus: differences in monosynaptic input to "slow" and "fast" abducens motoneurons. J Comp Neurol 498:762-785.
Uylings HB, Van Eden CG, Parnavelas JG, Kalsbeek A (1990) The prenatal and postnatal development of rat cerebral cortex. In: The cerebral cortex of the rat (Kolb B, Tees RC, eds), pp 34-76. London: MIT.

Viemari JC, Bévengut M, Burnet H, Coulon P, Pequignot JM, Tiveron MC, Hilaire G (2004) Phox2a gene, A6 neurons, and noradrenaline are essential for development of normal respiratory rhythm in mice. J Neurosci 24:928-937.

Voogd J (2004) Cerebellum. In: The rat nervous system, Ed 3 (Paxinos G, ed), pp 205-242. San Diego: Elsevier Academic.

Voogd J, Barmack NH (2006) Oculomotor cerebellum. Prog Brain Res 151:231-268.

Voogd J, Ruigrok TJ (2004) The organization of the corticonuclear and olivocerebellar climbing fiber projections to the rat cerebellar vermis: the congruence of projection zones and the zebrin pattern. J Neurocytol 33:5-21.

Voogd J, Pardoe J, Ruigrok TJ, Apps R (2003) The distribution of climbing and mossy fiber collateral branches from the copula pyramidis and the paramedian lobule: congruence of climbing fiber cortical zones and the pattern of zebrin banding within the rat cerebellum. J Neurosci 23:4645-4656.

Voogd J, Schraa-Tam CK, van der Geest JN, De Zeeuw CI (2012) Visuomotor cerebellum in human and nonhuman primates. Cerebellum 11:392-410.

Watson TC, Jones MW, Apps R (2009) Electrophysiological mapping of novel prefrontal-cerebellar pathways. Front Integr Neurosci 3:18.

Welker W (1987) Spatial organization of somatosensory projections to granule cell cerebellar cortex: functional and connectional implications of fractured somatotopy (summary of Wisconsin studies). In: New concepts in cerebellar neurobiology (King JS, ed), pp 239-280. New York: Alan R. Liss, Inc.

Wiesendanger R, Wiesendanger M (1982) The corticopontine system in the rat. II. The projection pattern. J Comp Neurol 208:227-238. 